\title{
EL COMERCIO TACNOARIQUEÑO DURANTE LA PRIMERA DÉCADA DE VIDA REPUBLICANA EN PERÚ, 1824-1836
}

\begin{abstract}
RESUMEN
Este artículo analiza las transformaciones experimentadas por el comercio de la región Tacna-Arica después de la independencia peruana. El aspecto más relevante de este proceso es el masivo arribo de mercaderes extranjeros, especialmente británicos, quienes intensificaron la integración de la economía regional a la economía mundial. Además, se examina la posición que ocuparon en este nuevo escenario los actores económicos provenientes del período colonial, como los mercaderes criollos y los arrieros.
\end{abstract}

Palabras clave: comercio, minería, república, extranjeros, británicos, Tacna, Arica, Perú, Bolivia.

\begin{abstract}
This article analyzes the transformations of commerce in the Tacna-Arica region after Peru's independence. The most relevant aspect of this process was the massive arrival of foreign merchants, especially British, who intensified the integration of the regional economy to world-wide economic networks. Moreover, the article examines the role economic actors from the colonial period, such as Creole merchants and muleteers had, under the new scenario generated after Peru's independence.
\end{abstract}

Key words: Commerce, Mining Industry, Republic. Foreigners, British, Tacna, Arica, Peru, Bolivia.

Fecha de recepción: agosto de 2009

Fecha de aceptación: mayo de 2010

Luego de conquistada su independencia en la batalla de Ayacucho (9 de diciembre de 1824), Perú emprendió un largo camino hasta alcanzar un régimen institucional estable, basado en el imperio de las leyes y legitimado por la soberanía de la nación. En su lugar, la violencia había dificultado la consolidación de las instituciones públicas; la carencia de una clase dirigente permitió que el poder político

* Doctor (c) en Historia, por la Pontificia Universidad Católica de Chile. Profesor del Departamento de Humanidades de la Universidad Andrés Bello. Correo electrónico: jaime.rosenblitt@bndechile.cl 
quedara a merced de caudillos militares, para quienes el Estado era un botín desde el cual combatir a sus enemigos y repartir prebendas entre sus incondicionales; y la falta de un mínimo consenso respecto de los intereses nacionales mantuvo en permanente riesgo la integridad del territorio ${ }^{1}$.

Construida sobre las ruinas del Estado colonial, desde sus inicios la República peruana estuvo atravesada por la violencia política, primero por las guerras de emancipación y luego por los caudillos militares y patriarcas regionales que se disputaban la conducción del gobierno nacional. Este escenario dejó poco espacio para que el protagonismo de la vida pública fuera asumido por hombres ilustrados, se impusieran el diálogo y la negociación, y el respeto a las leyes fuese la norma. En cambio, el empleo de la fuerza se transformó en un mecanismo político recurrente. En el aparato fiscal el panorama no era más optimista: el poder real del gobierno central no se extendía más que unas decenas de kilómetros fuera de Lima y los funcionarios públicos más importantes, como prefectos, subprefectos y gobernadores, ejercían su autoridad de forma autónoma, como si su poder fuera un patrimonio personal y no una delegación soberana de la nación ${ }^{2}$.

En este cuadro, que oscilaba entre la anarquía y la tiranía, solo con algunos paréntesis de normalidad institucional, el desarrollo de la economía y las actividades productivas dependían estrechamente del clima político, por lo que sus posibilidades de desarrollo en el largo plazo eran prácticamente nulas.

Para la economía tacnoariqueña, basada en el comercio marítimo y la arriería, la inestabilidad reinante durante la temprana República peruana solo imponía amenazas a su desenvolvimiento. Un aspecto sensible para los intereses regionales era el resultado de la discusión entre proteccionistas y librecambistas, respecto del modelo de desarrollo que debía adoptar el país.

Las posturas proteccionistas eran sustentadas por el poderoso gremio de comerciantes de Lima, agrupados en el Tribunal del Consulado, interesados en evitar el ingreso de competidores extranjeros al mercado local y mantener el intercambio cerrado de azúcar peruano por trigo chileno, vigente desde fines del siglo XVII. Junto a los mercaderes limeños estaban alineados diversos grupos de interés sectorial y regional, como los hacendados azucareros de las provincias de Piura y Truji1lo, a quienes cualquier apertura comercial dejaría indefensos frente a la competencia de sus pares caribeños y brasileños; los obrajeros de la sierra y los artesanos urbanos, amenazados por el masivo arribo de manufacturas noratlánticas, de inferior precio y superior calidad; y los molineros de Lima, que quedarían sin ocupación de permitirse que la harina estadounidense ingresara al mercado nacional y desplazara al trigo chileno ${ }^{3}$.

1 Una visión general de la política peruana en Jorge Basadre, La iniciación de la República: contribución al estudio de la evolución política y social del Perú, Lima, Fondo Editorial de la UNMSM, 2002 [1929-1930].

2 Cristóbal Aljovín de Losada, Caudillos y constituciones. Perú, 1821-1845, Lima, Pontificia Universidad Católica del Perú, Instituto Riva-Agüero, Fondo de Cultura Económica, 2000, 29-30.

3 Paul Gootemberg, Caudillos y Comerciantes. La formación económica del Estado peruano, 1820-1860, Cuzco, Centro de Estudios Regionales Bartolomé de Las Casas, 1997, 73-74. 
Al frente, el librecambismo era profesado por un pequeño pero influyente grupo de intelectuales y hombres públicos prestigiados durante la independencia, para quienes la libertad económica era una entre todas libertades cívicas y, por lo tanto, el modelo de desarrollo inherente a toda república. Junto a ellos, pero a partir de una visión pragmática, las élites agrícolas y mercantiles del sur peruano, especialmente del Departamento de Arequipa, eran firmes defensoras del liberalismo económico, puesto que, a diferencia de otras regiones, su inserción en el sistema capitalista mundial no estaba limitada al consumo de manufacturas, sino que disponía de una base exportadora mucho más dinámica y diversa, a partir de la cual ya no pagaban sus importaciones únicamente con metales preciosos, como el resto de Perú, sino que a la tradicional producción agrícola y vitivinícola habían sumado el algodón, la lana y la cascarilla procedentes de la sierra y los nitratos que comenzaban a explotarse en el desierto de Tarapacá ${ }^{4}$.

A este último grupo eran más afines los intereses de la región Tacna-Arica, pues compartían la necesidad de mantener un fluido intercambio con Bolivia, que desde la Colonia constituía el mercado natural de su producción agropecuaria y el origen de las exportaciones que transitaban por Arica. Para ello era indispensable mantener un régimen aduanero que no obstaculizara este flujo, imponiéndole cargas tributarias y administrativas. En definitiva, la prosperidad de todo el sur peruano descansaba en la estabilidad económica de Bolivia, que a su vez dependía del acceso de este país al puerto de Arica. Esta delicada situación fue descrita en 1826 por el cónsul británico Joseph Barclay Pentland:

"El comercio exterior a Bolivia se lleva a efecto hoy día exclusivamente desde el Puerto de Arica, pero las importaciones están sometidas a los impuestos peruanos, lo que movió a Bolivia a buscar el intercambio de las provincias de Arica y Tarapacá, a cambio de territorios bolivianos y la mitad de la deuda externa del Bajo Perú (5 millones de dólares), pero como el congreso peruano rechazó el tratado, se buscó estimular el desarrollo de Cobija"'5.

El rechazo del intercambio territorial por parte del Consejo de Gobierno peruano, en momentos en que el Estado estaba encabezado por el mariscal Santa Cruz y en que aún la opinión de Simón Bolívar tenía enorme gravitación en la política peruana, provocó que la competencia de Cobija, no obstante las dificultades para el transporte terrestre que suponía su ubicación, mermara la actividad portuaria de Arica e Islay, así como los ingresos de las aduanas peruanas, dando argumentos tanto a las posturas nacionalistas que promovían la hostilidad entre ambas naciones, como a las liberales, que encontraron una evidencia empírica de los perjuicios provocados por las restricciones al intercambio ${ }^{6}$.

\footnotetext{
$4 \quad$ Ibid., 252-253.

5 Joseph B. Pentland, Informe sobre Bolivia, Potosí, Editorial Potosí, 1978, 107-108.

6 Jorge Basadre, Historia de la República del Perú, Lima, Editorial Cultura Antártica [1946], I: 43-44; Jorge Ortiz Sotelo, Perú y Gran Bretaña: Política y economía (1808-1839), a través de los informes navales británicos, Lima, Asociación de Historia Marítima y Naval Iberoamericana, Instituto de Estudios Internacionales, Pontificia Universidad Católica del Perú, 2005, 121.
} 


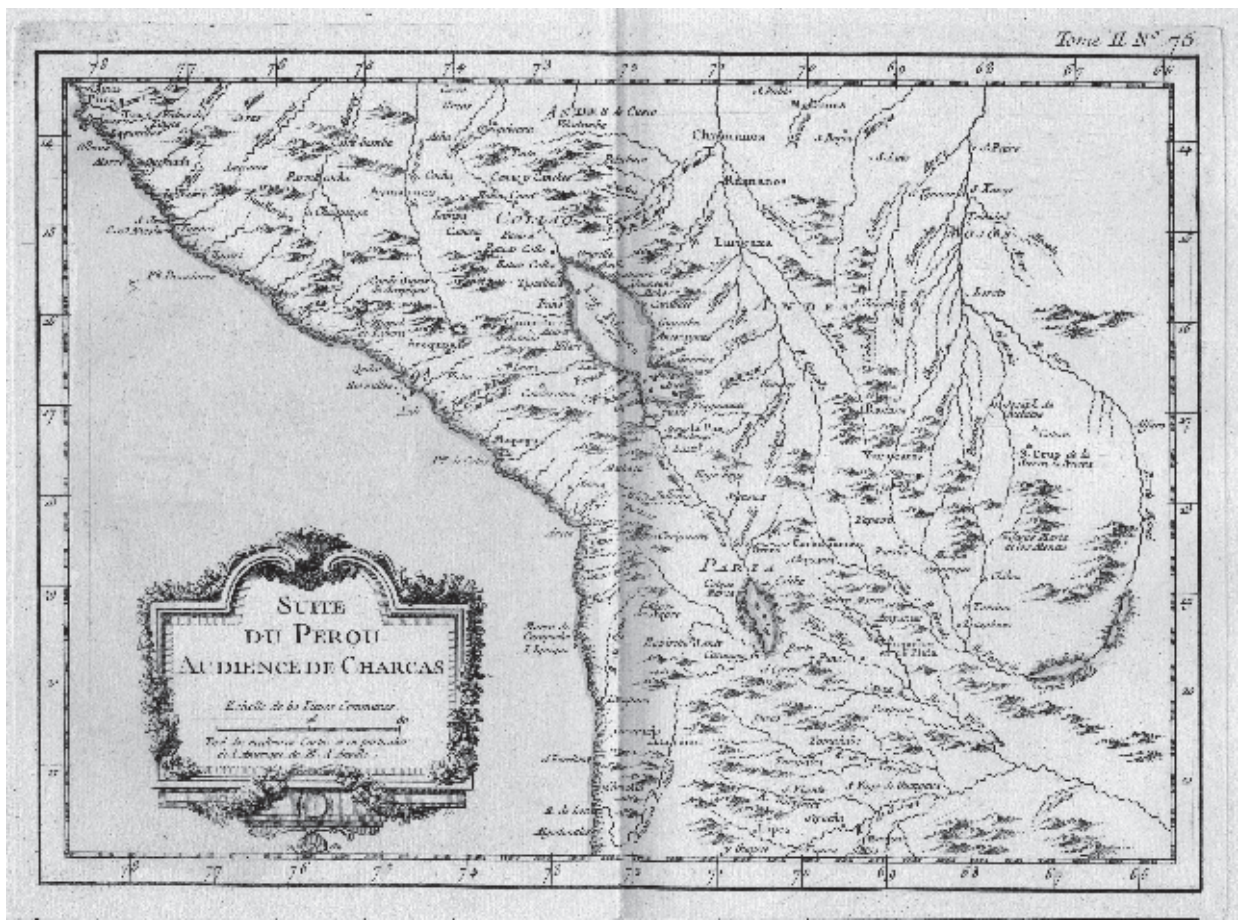

Audiencia de Charcas. En Jacques Nicolas Bellin, Le petit atlas maritime: recueil de cartes et plans des quatre parties du monde, París, s.n., 1764.

\section{EL COMERCIO EXTRANJERO}

Otro aspecto que acercaba al eje Tacna-Arica a los postulados del librecambismo sureño radicaba en la presencia de un abundante contingente de comerciantes extranjeros, especialmente ingleses, para quienes el liberalismo no solo suponía un entorno político favorable a sus intereses económicos, sino que además les ofrecía un sistema donde el imperio de las leyes los protegía de los abusos de la autoridad y garantizaba el respeto de sus derechos e identidad cultural. A falta de antecedentes cuantitativos, es difícil estimar la magnitud de la presencia de extranjeros en el sector mercantil tacnoariqueño a inicios del período republicano. Sin embargo, las impresiones del empresario minero británico Joseph Andrews, que visitó Tacna en diciembre de 1826, son elocuentes respecto de su predominio económico y sobre la necesidad de disponer de criterios comunes que garantizaran la continuidad de esta primacía, por lo menos a nivel local:

"Me percaté de que había tal influencia de mis compatriotas, que Tacna parecía ser más bien una colonia británica que una española. Es sorprendente ver como muy pronto cada vez que se abre un nuevo mercado a nuestro comercio es sobrepasado; es penoso constatar que todas nuestras energías orientadas al comercio son arrasadas por la competen- 
cia local; comerciantes y fabricantes devorándose los unos a los otros, especialmente los últimos que absorben las tres ramas o actividades: líneas navieras, comercio y manufactura en lugar de continuar cada uno de ellos con sus actividades específicas. Nada se puede esperar sino el infortunio de estos procedimientos" ${ }^{7}$.

La nutrida presencia de comerciantes británicos en la región Tacna-Arica tuvo características semejantes a la del resto de Hispanoamérica poscolonial, y de hecho debe ser concebida a partir de criterios que obedezcan antes a una estrategia general, que a la adaptación a la realidad singular de un territorio específico. En este sentido, aunque inicialmente los primeros empresarios británicos que se asentaron en la región, a semejanza de los peninsulares llegados en las dos últimas décadas del siglo XVIII, recurrieron a la colocación de grandes partidas de efectos manufacturados mediante operaciones de crédito, su permanencia en ella tuvo que ver con su inserción en el flujo de exportación de materias primas, primero corteza de cascarilla y algodón y más tarde lana, guano y nitratos ${ }^{8}$.

Otro rasgo de la mayor parte de los comerciantes extranjeros que actuaron en Tacna y Arica durante la primera mitad del siglo XIX es que formaban parte de redes mercantiles de amplia cobertura, que algunas veces actuaban por cuenta propia y otras como agentes de casas mayoristas establecidas en Lima y, especialmente, en Valparaíso.

La conexión con el puerto chileno era fundamental y una novedad respecto del período colonial, pues a mediados de la década de 1820 se había convertido en la principal plaza comercial de la cuenca del Pacífico y había sido escogido por las principales firmas británicas como lugar de destino de sus embarques de manufacturas, para desde ahí ser reexportadas hacia otros mercados de la región, como Perú, Bolivia, Ecuador y el noroeste argentino, que consumían hasta el $65 \%$ de los efectos de ultramar que llegaban a Valparaíso ${ }^{9}$. Estas importaciones eran pagadas con diversas materias primas que también arribaban al puerto desde aquellos mercados, para luego ser remitidas a Europa. En cierto sentido puede considerarse que, después de la independencia, los comerciantes ingleses instalados en Valparaíso que controlaban este circuito reemplazaron a los mercaderes peninsulares en el control de los grandes flujos del comercio exterior continental.

El rápido desarrollo de Valparaíso y su influencia en toda la costa del Pacífico sudamericano obedecen a que Chile alcanzó su independencia y liberalizó su comercio tempranamente, mientras que los demás países de la región aún estaban en

7 Joseph Andrews, Journey from Buenos Aires, through the provinces of Cordova, Tucuman, and Salta, to Potosi, thence by the deserts of Caranja to Arica, and subsequently to Santiago de Chili and Coquimbo, undertaken on behalf of the Chilian and Peruvian Minning Association in the years 1825-26, London, Shackell \& Baylis, 1827, II:173-174.

8 Esta estrategia, descrita por D.C.M Platt, Latin America and Bristish Trade, 1806-1914, New York, Barnes \& Noble, 1973, 23-29, prevaleció especialmente en mercados como el peruano, que, por los hábitos y capacidad de consumo de su extensa población indígena y mestiza, no resultaban demasiado atractivos para las importaciones noratlánticas.

9 Eduardo Cavieres, Comercio chileno y comerciantes ingleses, 1820-1880. Un ciclo de historia económica, Valparaíso, Universidad Católica de Valparaíso, 1988, 66; Jacqueline Garreaud, "La formación de un mercado de tránsito. Valparaíso: 1817-1848”, en Nueva Historia 11, Londres, 1984, 168. Ambos autores se basan en un informe del cónsul francés en Valparaíso. 
guerra con España; a que los conflictos políticos internos que aquejaron a Perú, Bolivia y la Gran Colombia durante las décadas de 1820 y 1830 los hicieron lugares poco atractivos para el asentamiento permanente de las casas comerciales extranjeras; y a que Valparaíso disponía de ventajas geográficas y de transporte (caminos, instalaciones portuarias y flota mercante) para conectarse físicamente con otras regiones del continente. A ello se agrega el hecho de que las autoridades chilenas emprendieron diversas medidas que favorecieron el desenvolvimiento portuario, como la permanente ampliación de la infraestructura de almacenamiento y la mantención de una política arancelaria liberal, que permitió a Valparaíso ser la principal plaza comercial del Pacífico durante el siglo XIX ${ }^{10}$.

En esta integración de los mercados hispanoamericanos en el comercio mundial, el eje Tacna-Arica se insertó como la puerta de ingreso de efectos manufacturados europeos destinados a las plazas del Alto Perú (ahora Bolivia), Arequipa y Tarapacá, y como el puerto de salida de las materias primas con que se pagaban las importaciones, intercambio que se realizaba desde el período colonial. El control de este flujo fue asumido por casas comerciales extranjeras establecidas en la región, mayoritariamente británicas, que operaban a través de agentes, quienes además emprendían actividades por su cuenta. Inicialmente, la posibilidad de acceder a un importante volumen de metales preciosos constituía el incentivo primordial para la presencia extranjera en la región, ya que las economías vinculadas al comercio tacnoariqueño tenían su base en la minería (Bolivia, Tarapacá), o recibían oro y plata a cambio de su producción agrícola (Arequipa).

Lo anterior se demuestra en el siguiente cuadro, que detalla los efectos embarcados en el puerto de Arica por la corbeta de guerra británica Alert durante 1828.

\begin{tabular}{|c|c|c|c|c|c|}
\hline Fecha & Remitente & Lugar de origen & Destinatario & Lugar de destino & Bienes remitidos \\
\hline 30 de marzo & Begg Atherson \& Co. & Arica & James Atherson & Liverpool & $\begin{array}{l}14 \text { piñas de plata ( } 77 \text { marcos y } 5,6 \text { onzas) y } 5 \text { barras de } \\
\text { plata ( } 10,5 \text { libras) }\end{array}$ \\
\hline 30 de marzo & Lezica Hermanos, Garcia y Cla. & Tacna & Lezica, Freres y Cia. & Valparaiso & $\begin{array}{l}111 \text { piñas de plata ( } 719 \text { marcos y } 5 \text { onzas) y } 3 \text { barras de } \\
\text { plata ( } 17 \text { marcos y } 1 / 4 \text { de onza) }\end{array}$ \\
\hline 15 de abril & Begg Atherson \& Co. & Tacna & Hebblethwaite, Walker \& Co. & Leeds & $\begin{array}{l}4 \text { cajas con } 12.0000 \text { pesos españoles; } 4 \text { cajas y } 3 \\
\text { paquetes con oro en polvo ( } 17 \text { libras y cuatro onzas) y } 29 \\
\text { piñas de plata ( } 79 \text { marcos y } 7 \text { onzas) }\end{array}$ \\
\hline 15 de abril & Begg Atherson \& Co. & Tacna & William Baxter \& Co. & Dundee & 1 caja con 1.500 pesos españoles \\
\hline 15 de abril & Begg Atherson \& Co. & Tacna & Hag Colin \& Co. & Manchester & 1.000 pesos españoles \\
\hline 15 de abril & Begg Atherson \& Co. & Tacna & James Alexander \& Co. & Glasgow & 477 pesos españoles \\
\hline 15 de abril & Begg Atherson \& Co. & Tacna & John Edwards & Manchester & 250 pesos duros \\
\hline 15 de abril & Begg Atherson \& Co. & Tacna & I. \& W. Kidd & Widness & 500 pesos duros \\
\hline 15 de abril & Begg Atherson \& Co. & Tacna & John Master \& Co. & Belfast & 500 pesos duros \\
\hline 15 de abril & Begg Atherson \& Co. & Tacna & Hind Smith \& Co. & Leeds & 3 piezas oro ( 279 onzas) \\
\hline 15 de abril & Begg Atherson \& Co. & Tacna & Desconocido & Inglaterra & 1 pieza de plata (5 libras y 3 onzas) \\
\hline 15 de abril & Huth Gruning \& Co. & Tacna & Frederick Huth & Londres & $\begin{array}{l}1 \text { caja con } 5.000 \text { pesos españoles y } 1.000 \text { pesos duros, y } \\
5 \text { piezas de oro ( } 251 \text { onzas) }\end{array}$ \\
\hline 15 de abril & Joseph Hegan & Arica & Desconocido & Inglaterra & $\begin{array}{l}29 \text { barras de plata ( } 159 \text { marcos y } 7 \text { onzas) y } 5 \text { piñas de } \\
\text { plata ( } 5 \text { marcos y } 4 \text { onzas) }\end{array}$ \\
\hline 15 de abril & Joseph Hegan & Arica & Dickinson Miller & Inglaterra & 5.000 pesos duros \\
\hline 15 de abril & Withington Crooke \& Co. & Tacna & Desconocido & Inglaterra & 1 caja con 2.100 pesos duros \\
\hline 15 de abril & Withington Crooke \& Co. & Tacna & Withington Meyers \& Co. & Liverpool & $\begin{array}{l}1 \text { caja con } 8 \text { piezas de oro; un paquete con oro en polvo } \\
\text { ( } 326 \text { onzas) y } 3.000 \text { pesos duros. }\end{array}$ \\
\hline 15 de abril & Horacio Bolton & Tacna & Samuel Winter & Londres & $\begin{array}{l}41 \text { barras de plata ( } 266 \text { marcos y } 5 \text { onzas); } 2 \text { bolsas y un } \\
\text { paquete con oro en polvo ( } 80 \text { ozas); } 2 \text { barras de oro ( } 25 \\
\text { onzas) y } 12.500 \text { pesos duros }\end{array}$ \\
\hline 15 de abril & Inglem McLaghlin & Tacna & William Henderson & Valparaiso & 3 cajas con 8.385 pesos duros \\
\hline 15 de abril & Inglem McLaghlin & Tacna & Charles Taylem, Sons \& Co. & Liverpool & $\begin{array}{l}48.615 \text { pesos duros; } 6 \text { barras de oro y } 3 \text { paquetes de oro } \\
\text { en polvo ( } 387 \text { onzas); } 5 \text { bolsas de oro en polvo ( } 420 \\
\text { onzas) y } 20 \text { barras de plata y } 16 \text { piñas de plata ( } 297 \\
\text { marcos y } 7 \text { onzas) }\end{array}$ \\
\hline 15 de abril & Inglem McLaghlin & Tacna & Heymouth Brothers & Rio de Janeiro & 2 cajas con 7.000 pesos españoles \\
\hline 15 de abril & Lezica Hermanos, García y Cia. & Tacna & Lezica, Feres y Cía. & Valparaiso & $\begin{array}{l}1.570 \text { pesos duros; } 4 \text { piezas de oro; } 2 \text { bolsas y dos } \\
\text { paquetes de oro en polvo ( } 17 \text { libras y } 8 \text { onzas) y monedas } \\
\text { de oro ( } 185 \text { onzas) }\end{array}$ \\
\hline 24 de junio & Withington Crooke \& Co. & Arica & Withington Meyers \& Co. & Liverpool & 757 pesos \\
\hline 14 de agosto & Withington Crooke \& Co. & Arica & Desconocido & Inglaterra & 1.713 pesos y 3 reales, 46.176 dólares \\
\hline 1 de noviembre & Desconocido & Arica & Desconocido & Valparaiso e Inglaterra & 6.000 pesos y 342 marcos y 2 onzas de plata \\
\hline
\end{tabular}

10 Garreaud, op. cit., 169-170; Cavieres, op. cit., 64; John L. Rector. "El impacto económico de la Independencia en América Latina: el caso de Chile", en Historia 20, Santiago, 1985, 295-318. 
Llama la atención que la totalidad de los bienes que ingresaron a las bodegas de la nave fueran metales preciosos, lo que obedece a que por el reducido espacio para carga disponible en un navío de guerra, se privilegió el traslado de los efectos más valiosos. También es necesario tener en cuenta que los antecedentes consignados corresponden a un momento temprano, en el que los mercaderes británicos llevaban apenas dos años instalados en la región y en que aún eran incipientes las actividades de exportación distintas a la minería de metales preciosos, capaces de cubrir el valor de las importaciones, como más tarde serán la lana, la cascarilla, el guano y el salitre.

Otro aspecto que destaca del cuadro anterior es que la mayor parte de los embarques estaba destinada a Gran Bretaña, donde las casas comerciales y los mercaderes que participaban en el flujo cancelaban a sus proveedores y depositaban sus utilidades. Ello puede ser producto de que por tratarse de una nave de la Real Armada, los comerciantes establecidos en Tacna y Arica privilegiaran trasladar en ella las remesas destinadas al Reino Unido, reservando los envíos hacia Valparaíso, Buenos Aires, Montevideo y Río de Janeiro a barcos mercantes propiamente tales. Sin embargo, la presencia de ambos puertos en la lista recopilada demuestra su posición axial, uno en el Pacífico y otro en el Atlántico, en el comercio británico en Sudamérica.

A diferencia de esta estrategia de penetración paulatina, una vez concluida la emancipación hispanoamericana un considerable número de capitalistas británicos se interesó por invertir directamente en la minería de las antiguas colonias españolas, pero su falta de conocimiento de las realidades locales, la geografía y sus exageradas expectativas los condujeron al fracaso.

Ejemplo de ello fue la Potosí, La Paz and Peruvian Minning Company, formada en Londres en abril de 1825, por iniciativa del guatemalteco Antonio José de Irisarri, representante del gobierno chileno en Gran Bretaña, Juan García del Río, embajador peruano, y el general James Paroissien, médico inglés que participó en las guerras de independencia en el Estado Mayor del general San Martín. Convencida de la rentabilidad que resultaría de la introducción de tecnologías modernas en la explotación de yacimientos hispanoamericanos trabajados durante la Colonia, la compañía contempló un capital inicial de un millón de libras esterlinas e integró en su directorio a seis miembros del Parlamento británico. Sus operaciones comenzaron en agosto de 1825, cuando llegó a Bolivia Alejandro Ganda con la tarea de arrendar y adquirir propiedades mineras en Potosí y organizar las faenas y su abastecimiento. En julio del año siguiente, recaló en Arica la nave Potosí, trayendo a bordo obreros europeos, provisiones, maquinarias e insumos para las faenas, las que quedaron a cargo de Paroissien y el químico austríaco Hermann von Czettritz. Mientras se ultimaban los preparativos para comenzar los trabajos, en agosto de 1826 llegaron noticias de Londres anunciando la bancarrota de la sociedad mineralógica. La crisis bursátil desencadenada en diciembre anterior había impedido recaudar la totalidad del capital proyectado inicialmente, por lo que la carga que había traído la Potosí desde Europa fue embargada en Arica para responder a los acreedores de la compañía, que debió 
suspender sus operaciones a comienzos de 1827, en procura de nuevos inversionistas que nunca aparecieron ${ }^{11}$.

Demostrada la inviabilidad de las inversiones directas en las actividades de exportación, la gravitación alcanzada por el comercio británico obedeció a que los mercaderes de esa nacionalidad estaban en condiciones de manejar grandes volúmenes de manufacturas y efectos elaborados, al punto que sus pares criollos y peninsulares que lograron sobrevivir a su arremetida solo lo hicieron al amparo de políticas proteccionistas, integrándose en sus circuitos como distribuidores minoristas o desplazándose hacia regiones periféricas. Su agresiva conducta empresarial les dio una ventaja adicional que resultó incontrastable para sus competidores nacionales ${ }^{12}$.

Un ejemplo de ello lo ofrece el caso de Joseph Hegan, en la primera operación comercial de un súbdito británico que aparece formalizada en la notaría de Tacna después de la independencia de Perú. La escritura data del 20 de mayo de 1825 y trata de la adquisición de un esclavo ${ }^{13}$. Aunque la transacción pudiera ser apenas un detalle de escasa relevancia, pues Hegan desembolsó 300 pesos por el zambo de 16 años, surge la comparación con los mercaderes criollos y coloniales, que incursionaban en el tráfico negrero una vez que sus demás actividades les habían allegado cierta prosperidad y prestigio, y cuando adquirían esclavos para el servicio personal era porque habían alcanzado una posición holgada ${ }^{14}$. En cambio los británicos, que por lo menos en este período no practicaban este tipo de comercio, adquirían esclavos para que los ayudaran en sus actividades, ya sea como cargadores, mensajeros o auxiliares de despacho. Entonces, tras la compra del esclavo, subyace el hecho de que Joseph Hegan llegó a Tacna con un capital inicial de cierta consideración y contemplaba realizar operaciones de envergadura, que no ameritaban desperdiciar el tiempo en tareas menores para ahorrar algunos centenares de pesos.

Después de instalar una bodega mayorista en el pueblo, Joseph Hegan comenzó a tender una red de contactos para colocar sus productos en Bolivia y Arequipa, plazas donde contaba con una nutrida demanda. Una fórmula para acceder a esos mercados era la misma que habían utilizado los mercaderes coloniales, que consistía en adelantar mercaderías a un arriero, quien las comercializaría por su cuenta y obtendría la utilidad correspondiente al interés del crédito. Una relación de este

11 Enrique Tandeter, Coacción y Mercado. La minería de la plata en el Potosí colonial, 1692 1826, Cusco, Centro de Estudios Regionales Andinos Bartolomé de Las Casas, 1992, 275-285.

12 Juan Eduardo Vargas, José Tomás Ramos Font. Una fortuna del siglo XIX, Santiago, Fundación Mario Góngora, Ediciones Universidad Católica de Chile, 1988, 50-51. El autor describe las actividades de Álvarez y Cía, de Valparaíso, a comienzos de la década de 1830. La compañía era propietaria de algunos barcos que recorrían el litoral entre El Callao y Chiloé. De cada puerto sacaba materias primas locales que después vendía en Valparaíso, donde además adquiría manufacturas a diferentes casas británicas allí establecidas, para luego colocarlas de Talcahuano al sur.

13 Archivo Nacional Histórico. Fondo Notarios de Arica (ANA), legajo (leg) 70, fojas (fs) 106107.

14 Jaime Rosenblitt, "Las reformas borbónicas en el partido de Arica", en Hernán Cortés y Milton Godoy (editores), La historia regional y su pasado presente: XII Jornadas Nacionales de Historia Regional de Chile, La Serena, Ediciones de la Universidad de La Serena, 2007, 147-155. 
tipo estableció con Francisco Vásquez, a quien en febrero de 1826 adelantó efectos de ultramar por 3.164 pesos con 6 reales, pagaderos en seis meses con un interés de $3 \%{ }^{15}$.

Pero esta modalidad comportaba varios riesgos, puesto que además de los peligros que asechaban a cualquier expedición de arriería a través de la sierra, los troperos eran empresarios informales que contaban con escasos bienes con que respaldar sus compromisos en caso de no poder cubrir sus deudas, por lo que Hegan optó por evitar este tipo de clientes y acceder directamente a los mercados de consumo, a través de agentes y consignatarios. Así, en diciembre de 1826 designó al cochabambino Agapito Acha representante en Bolivia y, poco después, a Francisco de los Heros apoderado en Arequipa. A través de este último logró llegar a un acuerdo con el catalán Santiago Igualt para intercambiar sus importaciones por los productos alimenticios que este mercader controlaba, logrando así diversificar la oferta de bienes que colocaba en Bolivia ${ }^{16}$.

Con el tiempo, Hegan agregó nuevos artículos americanos a la cartera de productos que ofertaba en el altiplano, como el cacao que su hermano John adquiría en Lima y que trocaba por cascarilla con el tarapaqueño Manuel Loayza, a razón de 10 pesos por cada quintal de cacao amargo puesto en La Paz y 3 pesos por libra de cascarilla descargada en el puerto de Arica ${ }^{17}$; o el aceite que obtenía del moqueguano Lucas Fernández Maldonado, con quien suscribió un contrato para recibir mil arrobas anuales entre 1829 y $1832^{18}$. Sin embargo, y a pesar de los esfuerzos por disponer de una oferta variada, la fortaleza comercial de Hegan continuó descansando en la distribución de manufacturas.

En este aspecto, cabe destacar que, hasta 1833, Joseph Hegan operó en forma independiente de las casas comerciales británicas establecidas en Valparaíso, por lo que debía entenderse directamente con los proveedores o vincularse con distribuidores que le permitieran ofrecer precios equivalentes a sus compatriotas que se abastecían en el puerto chileno.

Un antecedente al respecto es el poder amplio de representación que entregó a Thomas Wentworth, el 10 de marzo de 1827, para que se dirigiera a Montevideo y tramitara ante las autoridades uruguayas la liberación de sus mercancías traídas desde Inglaterra a bordo de la fragata San Salvador y confiscadas por razones administrativas. En el documento se menciona que los detalles del caso están en poder de A. Cavaillon, cónsul francés en la capital uruguaya, quien estaba investido de poderes de representación para atender los asuntos de Hegan en ese país ${ }^{19}$. Además del contacto en Montevideo, que le permitía acceder a saldos y liquidaciones que pudiera ofrecer el comercio británico en el Río de la Plata y Brasil, Joseph Hegan estaba atento a cualquier oportunidad de obtener manufacturas a bajo costo. Una ocasión se le presentó a mediados de 1828, cuando compró a Thomas

15 ANA, leg. 72, fs. 170v-171v, 25 de febrero de 1826 .

16 ANA, leg. 72, fs. 37v-38v, 22 de diciembre de 1826; ANA, leg. 73, fs. 10-10v, 21 de enero de 1827 y fs. 20-20v, 27 de enero de 1827 .

17 ANA, leg. 73, fs. 121-122, 26 de julio de 1827.

18 ANA, leg. 77, fs. 211-211v, 10 de febrero de 1829.

19 ANA, leg. 73, fs. 41-41v, 10 de marzo de 1827. 
Crompton una deuda del estadounidense Maskline Clark por 1.925 pesos. A fines de julio de ese año, aprovechó un viaje del escocés John Macfadon a Filadelfia para efectuar el cobro, pero además lo autorizó para recibir el pago en especies, caso en el que el monto de la obligación se reduciría en 275 pesos $^{20}$.

Los negocios de Hegan continuaron afirmándose en la colocación de manufacturas en el altiplano hasta que regresó a Liverpool, en octubre de 1833. Sus intereses quedaron entonces al cuidado de su hermano John, quien dos meses antes había formado en Lima la sociedad Hegan \& Hall, dedicada a la explotación minera ${ }^{21}$.

La compañía comenzó a operar adquiriendo la mina Veracruz y el socavón Salcedo, yacimientos de cobre en el asiento de Choquelimpe, en la precordillera frente a Arica, y designó a William Hillman como agente en Valparaíso, a cargo de la comercialización de la producción y la adquisición de maquinarias y bastimentos $^{22}$. Posteriormente se vinculó a la emergente explotación del nitrato en Tarapacá mediante varios contratos celebrados con George Smith ${ }^{23}$, en los que Hegan y Hall se encargaban de conseguir mulas y arrieros para el traslado de la producción de las oficinas De la Peña y Colombia, explotadas por Smith, a los puertos de Iquique y Pisagua ${ }^{24}$.

Esta experiencia permitió a Hegan y Hall, en 1836, encontrar un lugar en el negocio salitrero donde aprovechar al máximo sus cualidades, las que claramente no estaban en la explotación directa de los depósitos mineros, sino en la comercialización de la producción y la habilitación de las faenas de pequeños mineros. En febrero de ese año suscribieron un convenio con Fernando de Oviedo, vecino de Camiña, y otro con los hermanos Santiago e Ildefonso Zavala, chilenos avecindados en Tacna, mediante los cuales estos se comprometían a entregar determinada cantidad de quintales de salitre a Hegan y Hall en el puerto de Pisagua, y a cambio de ello la sociedad les adelantaba mulas, alimentos, herramientas y ropa, quedando un saldo a favor de los mineros que debía ser cancelado cuatro meses después de la entrega del nitrato ${ }^{25}$.

La sociedad Hegan y Hall continuó hasta 1839 realizando este tipo de operaciones, tras las cuales subyacen varias ventajas operacionales logradas por los hermanos Hegan, luego de más de una década de experiencia en la costa del Pacífico sudamericano y en el mercado regional. En primer lugar están sus vínculos con las

20 ANA, leg. 77, fs. 135-135v, 28 de julio de 1828 .

21 ANA, leg. 81 fs. $182 \mathrm{v}-183 \mathrm{v}, 10$ de agosto de 1833 ; fs. 99-99v, 3 de octubre de 1833 .

22 ANA, leg. 81, fs. 32-32v, 25 de noviembre de 1833; ANA, leg. 84, fs. $127 \mathrm{v}-128 \mathrm{v}, 9$ de agosto de 1834.

23 George Smith fue un pionero del desarrollo de la industria del salitre en Tarapacá durante el siglo XIX. Su aproximación a la actividad se remonta a 1827, cuando él y William Bollaert fueron contratados por el general Ramón Castilla, gobernador de la provincia, para hacer un reconocimiento del desierto, identificar los principales yacimientos de nitrato de soda y borato de cal y proponer formas para su explotación y exportación. El estudio fue entregado al gobierno peruano y en 1851 se tradujo en un mapa que graficaba sus resultados y conclusiones. William Bollaert, Antiquarian, ethnological and other researches in New Granada, Equador, Peru and Chile: with observations on the preincarial, incarial, and other monuments of peruvian nations, London, Trübner \& Co., 1860, 154-155.

24 ANA, leg. 83, fs. 19-19v, 19 de junio de 1835; ANA, leg. 85, fs. 83-85, 19 de junio de 1835.

25 ANA, leg. 86, fs. 491-492v, 2 de febrero de 1836; fs. 92-93 y 498-500, 9 de febrero de 1836 
redes mercantiles europeas y británicas que operaban en Valparaíso, a partir de las cuales podían obtener todo tipo de manufacturas importadas, bienes de capital, crédito y compradores para la producción minera que controlaban; luego, su inserción en el comercio tacnoariqueño los puso en contacto con diferentes actores del proceso minero que era preciso coordinar para poner en funcionamiento la producción, como inversionistas europeos con escaso conocimiento de la economía regional, propietarios de estacas y yacimientos, técnicos carentes de capital, empresarios locales desvinculados del mercado internacional, proveedores de manufacturas y alimentos, y muleros dispuestos a participar como transportistas en las diferentes fases de las faenas mineras. En definitiva, si la etapa minera es la culminación de una carrera empresarial europea en la región, el comercio de manufacturas corresponde al momento de inserción y generación de los contactos que más tarde permitirán la organización de emprendimientos más complejos y rentables, como la minería.

Otro comerciante inglés que, al igual que los hermanos Hegan, inició sus negocios en la región de manera autónoma a las firmas comerciales británicas que operaban en las costas del Pacífico a partir de sucursales en Valparaíso fue Horatio Bolton.

Si bien carecía de contactos en el Viejo Mundo como para prescindir de este puerto como fuente de abastecimiento de manufacturas, Bolton contaba con sólidos vínculos en Bolivia que le permitían colocar grandes partidas de bienes en ese mercado, sin necesidad de actuar como agente de otros distribuidores o recurrir a consignatarios locales que redujeran el margen de sus utilidades. Esto porque antes de afincarse en Tacna tuvo un paso por ese país y el Río de la Plata, donde estableció acuerdos con actores posicionados en los mercados altiplánicos como mayoristas.

La importancia de sus relaciones se desprende del hecho de que su primera aparición en la notaría tacneña, en agosto de 1826, correspondiera al cobro de 1.000 pesos a William Black, por una letra que este había suscrito un mes antes en Sicuani para afianzar un préstamo que el mariscal José Antonio Sucre negociaba en Buenos Aires ${ }^{26}$.

Luego, otra particularidad que permite suponer que sus contactos en el altiplano eran algo más que redistribuidores de manufacturas importadas es que Bolton lograba colocar grandes partidas de añil en esa plaza, como 4.500 libras a la sociedad formada por Miguel Ibarnegaray, Lorenzo Eguren y José de los Castaños, 1.500 a Prudencio Núñez y 3.500 a Lucas Delfín, entre otros, entre marzo y abril de 1827, alcanzando la suma de 25.110 pesos sus ventas en este rubro ${ }^{27}$. El añil, originario de Centroamérica y empleado en toda la región de los Andes centrales para el teñido de lanas, era obtenido en las sucursales limeñas de Templemann \& Bergmann y Brittain, Waddington \& Co., a las cuales Bolton representaba además en el cobro de obligaciones a residentes en Tacna y Moquegua ${ }^{28}$.

26 ANA, leg. 72, fs. 68-68v, 14 de agosto de 1826.

27 ANA, leg. 73, fs. 50-50v, 17 de marzo de 1827; fs. 51-51v, 22 de marzo de 1827; fs. 67-67v, 12 de abril de 1827 .

28 ANA, leg. 73, fs. 193v-194, 16 de noviembre de 1827; fs. 194v-195v, 26 de noviembre de 1827. 
Tal vez el aspecto más provechoso del vínculo de Bolton con las agencias mercantiles británicas era la posibilidad de obtener azogue a buen precio en Valparaíso $^{29}$. Aún en Perú y Bolivia el mercurio disfrutaba de un alto precio, pues debido a la declinación de las minas de Huancavelica y la suspensión de las remesas directas desde España, su oferta no era suficiente para cubrir los requerimientos de los beneficiadores de plata.

Avecindado en Tacna ${ }^{30}$, Bolton conoció a los empresarios locales Juan Antonio Castañón, Gregorio Arce y Juan Bautista Pomadera, dedicados a la distribución de mercurio en Tarapacá y al procesamiento de la producción de pequeños mineros regionales de los asientos de Mecalaco y Choquelimpe, para lo cual habían habilitado un plantel en una hacienda del valle de Sama, propiedad de Arce, dotado con hornos a leña y bateas de fierro para la amalgamación del mineral ${ }^{31}$.

El 12 de julio de 1827, Bolton puso a disposición de los fundidores tacneños, en el puerto de Arica, una partida de 585 quintales de azogue. La remesa era parte de un cargamento mayor adquirido en Cádiz por la sucursal en Valparaíso de la casa Brittain \& Waddington y su precio de venta fue de 32.757 pesos, los que fueron asumidos en partes iguales por los socios, en letras canceladas puntualmente en 30, 60 y 90 días $^{32}$.

Aunque a lo largo de su trayectoria comercial Horatio Bolton siempre se ocupó de la colocación de manufacturas importadas en el sur peruano y en Bolivia, la experiencia con la distribución de azogue derivó en la configuración de dos características singulares de su perfil empresarial. La primera dice relación con su incorporación a la minería, mediante la formación de una sociedad con el irlandés Thomas Armstrong, denominada Compañía de Minas de Plata de Choquelimpe, a la que aportó capital y maquinarias para la explotación de las estacas descubiertas por Armstrong ${ }^{33}$. La segunda es que paulatinamente fue dejando de ser un comerciante independiente para convertirse en el representante local de Joshua Waddington ${ }^{34}$.

Hasta mediados de 1833 , la casa Brittain \& Waddington mantuvo una agencia en Tacna de la que Bolton era cliente. A partir de la disolución de la sociedad con Charles Brittain y producto de un mandato entregado en Valparaíso, Horatio Bolton se hizo cargo de la administración de los bienes e intereses de Waddington en

29 Rector, op. cit., 303.

30 En febrero de 1828 , Bolton arrendó una chacra regada en la cabecera del pueblo a Pedro Antonio Cornejo y dos topos continuos a esta a Jacinto y José María Liendro. Ambos contratos son a nueve años y consideran un canon de 50 pesos anuales. En el caso del terreno de los Liendro, se indica en la escritura que allí Bolton está construyendo una casa habitación para su familia. ANA, leg. 75, fs. 7-7v.; ANA, leg. 77, fs. 11-13v, 1 de febrero de 1828 .

31 ANA, leg. 77, fs. 363-370v, 5 de octubre de 1829. Testamento de Gregorio Arce.

32 ANA, leg. 73, fs. 109-109v, 12 de julio de 1827. La oportuna cancelación de las letras se consigna en anotaciones en el margen del documento.

33 ANA, leg. 84, fs. 249v-250v, 18 de marzo de 1834.

34 Arribado a Valparaíso en 1817, a los 25 años de edad, Joshua Waddington llegó a ser considerado el capitalista más poderoso de esa plaza durante la década de 1830. A través de su sociedad con George Templemann, distribuyó mercaderías a lo largo de todo el Pacífico sudamericano, lo que explica su presencia en Tacna. A partir de la década siguiente, sus intereses se reorientaron hacia la minería en el norte chileno. Virgilio Figueroa, Diccionario histórico biográfico y bibliográfico de Chile, Santiago, Imprenta y Litografía La Ilustración, 1925-1931, V:1078-1079. 
Tacna y el cobro de obligaciones a su favor en Bolivia y las provincias del sur peruano. Aunque nunca medió entre ambos empresarios una subordinación formal y cada uno mantuvo su autonomía, en la práctica Bolton se convirtió en una suerte de agente de Waddington en Tacna, ya que el británico afincado en Valparaíso, mediante compras a crédito y al contado, se convirtió en el proveedor exclusivo de las manufacturas importadas que este colocaba en el altiplano ${ }^{35}$.

En general, todas las casas comerciales británicas que operaron en la costa del Pacífico durante las dos décadas que siguieron a la independencia establecieron sucursales en Tacna o, por lo menos, efectuaron negocios en la región, aunque cada una actuó con una modalidad propia. Si bien las cualidades geográficas del eje Tacna-Arica ofrecían la posibilidad de acceder a atractivos mercados de consumo en Bolivia y el sur peruano, así como participar en el negocio minero y en flujos de exportación de bienes con una creciente demanda en Europa, como la lana y la cascarilla, en muchos casos el arribo de las firmas mercantiles extranjeras a la región obedeció a motivos indirectos y circunstanciales, más que a una estrategia premeditada.

Esto queda demostrado en las primeras escrituras que estas empresas suscribieron en las notarias de Tacna y Arica, a las que enviaban a sus apoderados con el fin de ejecutar compromisos contraídos por lugareños en otras plazas, como Lima, Valparaíso, Santiago y Buenos Aires, y que frecuentemente dejaban de cumplir. El primero de estos documentos corresponde al cobro de una deuda de 14.217 pesos, contraída por José María Basadre en Valparaíso el 26 de diciembre de 1825. La suma fue proporcionada a Basadre por el santiaguino Pedro Nolasco Mena para la adquisición de bienes importados en la casa Bunster y Widder de Valparaíso, a través de dos letras que vencieron cuatro meses después de su rúbrica. Luego de cumplido el plazo establecido el 11 de mayo de 1826, William Swinburn se presentó en la escribanía de Tacna a hacer efectivo el compromiso, como representante de la sucursal en Valparaíso de la matriz bonaerense de Withington, Crooke \& Co., que había adquirido el documento ${ }^{36}$.

Un cobro de distinta naturaleza fue el que llevó a la casa española Lezica Hermanos y García, de Valparaíso, a instalarse en Tacna, ya que una carga de 70 zurrones de tabaco bracamoro, embarcada en El Callao a bordo de la goleta peruana Amistad, en agosto de 1827, debía haber sido entregada en el puerto de Arica a un representante del comerciante limeño Eugenio Roset. Como el traspaso nunca se efectuó y no hubo rastros de la nave, el 20 de diciembre de ese año Sebastián Lezica se presentó ante las autoridades requiriendo antecedentes sobre el paradero de la embarcación, su comandante y la mercancía ${ }^{37}$.

35 Los poderes que recibió Bolton para representar a Joshua Waddington en Tacna constan en ANA, leg. 84, fs. 78v-80, 4 de noviembre de 1834, documento en que se transcribe un poder inicial formalizado en Valparaíso en diciembre de 1833. En cuanto a las operaciones comerciales, Bolton representó a Waddington en numerosas ocasiones, casi todas bajo la modalidad de adelanto, pago en cuotas con intereses e hipoteca de inmuebles.

36 ANA, leg. 72, fs. 125-126.

37 ANA, leg. 73, fs. 214-214v. 
Huth, Gruning \& Co., otra importante casa británica en el Pacífico, también arribó a Tacna para hacer efectivo el cumplimiento de compromisos contraídos en otros lugares. En este caso se trataba de una letra librada en Arequipa por la sociedad Dubern y Rejo, de Valparaíso, a favor del alemán Daniel Schutte por 3.455 pesos. El documento había vencido el 1 de diciembre de 1828 y diez días después se presentó en la oficina del escribano de Tacna Christian Hellmann, apoderado de Huth Gruning, reclamando a Esteban Casey, agente de Dubern y Rejo en la villa, el pago de la deuda ${ }^{38}$.

No obstante la similitud del origen de sus sucursales locales, las agencias de estas firmas extranjeras en Tacna tuvieron un desenvolvimiento completamente diverso. Por ejemplo, Withington, Crooke \& Co. se especializó en el cobro de obligaciones para otras filiales sudamericanas de la empresa o para terceros que la requerían para el mismo servicio desde otras plazas.

Un caso del primer tipo se presentó con ocasión de dos contratos, celebrados el 24 de agosto y el 2 de octubre de 1826, entre las oficinas en Buenos Aires de Withington Crooke y Green \& Hodges, por medio de los cuales los segundos se comprometieron a entregar 500 quintales de cascarilla calisaya de primera calidad puesta Valparaíso, a razón de 6 pesos por quintal. Ambas partidas fueron canceladas por adelantado, una vez signadas las escrituras, permitiendo a los compradores obtener una rebaja del 4\%. Las dificultades comenzaron en Arica, a fines de noviembre de 1826, cuando Thomas Crooke inspeccionó personalmente la primera remesa de 200 quintales que llegó desde Potosí para ser embarcada a Valparaíso, comprobando que era de pésima calidad. La situación no mejoró a fines de enero de 1827, cuando el segundo despacho llegó a Arica, ya que en lugar de 300 quintales venían 150, también de cuestionable calidad. Inmediatamente William Swinburn interpuso un recurso judicial contra Pedro Vidal, representante de Green Hodges en Tacna, y Manuel José Haedo, empresario potosino responsable de la entrega de la mercadería en Arica. En la acción, Swinburn demandó la restitución de la totalidad del dinero cancelado por Withington Crooke en Buenos Aires (2.880 pesos), más el $0,5 \%$ de interés mensual como sanción ${ }^{39}$.

Además, la agencia de Withington Crooke cobraba deudas en Tacna y Arica para comerciantes de otras plazas sin medios o tiempo para hacerse presentes en la región. Una de las tantas ocasiones en que su apoderado en Tacna, William Swinburn, debió cumplir dicha tarea fue en abril de 1827, cuando requirió a William Black 1.200 pesos por una letra girada por Nicholas Watson, en su representación, a Cochrane \& Robertson, en Lima, el 28 de septiembre de 1826 . O en julio de 1827 , cuando Swinburn inscribió en la notaría de Tacna los poderes de representación entregados en Lima por James Moure a Withington Crooke, para cobrar compromisos a su favor en el Departamento de Arequipa y la República de Bolivia. Probablemente de este mandato se deriva el nombramiento de Tomás Marín como

38 ANA, leg. 77, fs. 173-173v.

39 ANA, leg. 72, fs. 25-25v, 29 de noviembre de 1826; leg. 73, fs. 23-24v, 3 de febrero de 1827. 
representante de los asuntos de la compañía y sus representados en ese país, como Ferdinand O'Connor, residente en Potosí y deudor de Moure ${ }^{40}$.

Con todo, parce ser que la presencia en Tacna de la casa Withington, Crooke \& Co. fue solo eventual y que, más que un agente, William Swinburn era un cliente local que le prestaba servicios de representación en circunstancias muy precisas. Esto queda demostrado en el hecho de que en la única ocasión en que una operación importante de la firma tuvo lugar en la región -la adquisición de 500 quintales de cascarilla-, uno de sus socios se trasladó personalmente hasta Arica para velar por los intereses de la empresa, aunque después delegó en una tercera persona las gestiones judiciales que se derivaron del fallido negocio.

El caso de Lezica Hermanos y García es semejante al de Withington Crooke, en cuanto a que su representante en Tacna estaba dedicado a efectuar cobranzas para la matriz de la compañía en Valparaíso y las sucursales en Lima y Potosí. Esta estructura fue aprovechada poniéndola a disposición de otras firmas y particulares que carecían de representantes en la plaza, con el fin ejecutar obligaciones contraídas por residentes en Tacna, Arica y Moquegua en otros lugares, representarlas judicialmente o, simplemente, adquiriendo letras vencidas con la certeza de disponer de los medios para cobrarlas.

Entre 1828 y 1833 , Lezica Hermanos efectuó estas operaciones doce veces, siendo las más importantes el cobro de 11.000 pesos a Horatio Bolton en junio de 1829, por dos letras giradas en Valparaíso un mes antes por Turner, Smith \& Co., a favor de Francisco Javier Rosales ${ }^{41}$; el cobro de 2.500 pesos a las dependencias en Tacna de Dubern y Rejo, por una letra ya vencida y adquirida en La Paz a su titular, Juan Ghersi ${ }^{42}$; y la recuperación para Gibbs, Crawley \& Co., en mayo de 1832, de la mercadería embarcada a bordo de la fragata inglesa Lucy, incautada en la Aduana de Arica cuando cubría la ruta entre Valparaíso y El Callao, por no tener la documentación exigida para ser internada en Perú ${ }^{43}$.

Pero la principal fortaleza de Lezica estaba en las facilidades de que disponía para acceder al mercado boliviano con los efectos de ultramar que llegaban a su sede en Valparaíso. Para articular este circuito contaba con un agente en Tacna, Diego Taenius, aunque en varias ocasiones Sebastián Lezica se presentó en el pueblo con el objeto de entenderse personalmente con sus clientes altiplánicos. Cuando el flujo de los negocios con el mercado boliviano alcanzó una magnitud que impedía atenderlos a distancia, se resolvió nombrar agente permanente a Federico Schwager, mercader alemán residente en Potosí ${ }^{44}$.

Sin embargo, la llegada de Agustín Gamarra a la presidencia de Perú a fines de 1829 agudizó el clima de tensión entre esta nación y Bolivia, y provocó una sensible reducción del comercio a través del puerto de Arica, luego de la habilitación de

40 ANA, leg. 73, fs. 65-66v, 11 de abril de 1827; fs. 120v-121, 26 de julio de 1827.

41 ANA, leg. 77, fs. 314-315v, 3 de junio de 1829 .

42 ANA, leg. 78, fs. 398-398v, 9 de febrero de 1830

43 ANA, leg. 78, fs. 156-156v, 2 de mayo de 1832.

44 Archivo Nacional Histórico. Fondo Notarios de Tacna (ANT), leg. 12, fs. 47-47v, 10 de julio de 1830 . 
Cobija al comercio exterior ${ }^{45}$. Por ello, en octubre de 1830 Lezica Hermanos resolvió abrir una sucursal en el flamante puerto boliviano, tarea que fue encomendada al administrador del despacho en Valparaíso, Pascual Lynch, quien desapareció a comienzos de 1831 , luego de emprender un viaje por tierra a Iquique ${ }^{46}$.

Finalmente, otra firma que llegó a Tacna con el propósito de cobrar deudas específicas, pero terminó abriendo una agencia local, fue la británica Huth, Grunning \& Co. Christian Hellmann se hizo cargo de la sucursal, especializada en la distribución de géneros rústicos en los tradicionales mercados del sur peruano y Bolivia. Sus principales clientes eran mercaderes bolivianos que compraban telas y paños a crédito, como el potosino Manuel María Forero, que en julio de 1830 retiró 30 piezas de bayeta de pellón, a razón de 30 pesos cada una, pagaderas en una sola cuota dentro de cinco meses y con una multa de $0,5 \%$ por cada mes de mora.

Otro mayorista altiplánico que recurrió a una modalidad de compra similar fue el paceño Ignacio del Castillo, que ese mismo mes reconoció una obligación por 3.150 pesos, correspondientes a 15 fardos con 45 cabos de bayeta de pellón que había retirado de la Aduana de Arica, cancelando por su cuenta los derechos fiscales comprometidos. El plazo para el cumplimiento de la deuda fue de siete meses, con $0,5 \%$ de interés por cada mes de atraso.

Un tercer comerciante boliviano que regularmente se surtía en la sucursal de Huth Grunning en Tacna era el cochabambino Mariano Solís, quien en enero de 1834 adquirió una importante partida de efectos de Europa. La remesa fue por un total de 2.436 pesos, pagaderos en cuatro meses, con la habitual multa de medio punto de interés por cada mes de retraso ${ }^{47}$.

Al igual que muchas otras casas comerciales extranjeras que atendían el flujo entre Valparaíso y El Callao, Huth Grunning desembarcaba diversos bienes importados y productos agrícolas chilenos en el puerto de Arica para atender pedidos de los mercaderes que operaban a nivel local y regional. Así, a lo largo de 1828 trajo desde Valparaíso más de 12.500 pesos en diversos tipos de efectos, como géneros ingleses, ropa, quincallería, menaje, cosméticos, instrumentos musicales y harina, en tanto que la sucursal de Lima envió casi 2.100 pesos en telas, algodón en bruto y cristalería ${ }^{48}$.

Para atender estos negocios, que generalmente suponían operaciones crediticias, la labor de Christian Hellmann se hizo insuficiente, por lo que se recurrió a la colaboración de Daniel Schutte, alemán avecindado en Arequipa. Su colabora-

45 La habilitación del puerto de Cobija la Mar supuso una actitud de abierta hostilidad del gobierno boliviano al peruano, por la sensible caída que esta medida provocó en los ingresos fiscales que Perú recaudaba a través de la Aduana de Arica. Una dimensión de este perjuicio está en el volumen de importaciones que ingresaba por el puerto boliviano, que de 80.117 pesos en 1828, aumentó a 852.032 pesos en 1832. Ortiz, op. cit., 121 y 154 .

46 ANA, leg. 78, fs. 340-340v, 18 de marzo de 1832. Diego Taenius encarga a Federico Schawger dirigirse a Cobija y examinar la contabilidad y toda la documentación existente en la agencia de Lezica y Cía. en ese puerto, para encontrar pistas sobre el destino o paradero de Lynch.

47 ANT, leg. 12, fs. 45-45v, 2 de julio de 1830; fs. 46-46v, 8 de julio de 1830; ANA, leg. 84, fs. 303-303v, 4 de enero de 1834.

48 Estos antecedentes fueron recopilados en el Archivo de la Aduana de El Callao por la doctora Ana Cristina Mazzeo, de la Pontificia Universidad Católica del Perú, quien los facilitó gentilmente. 


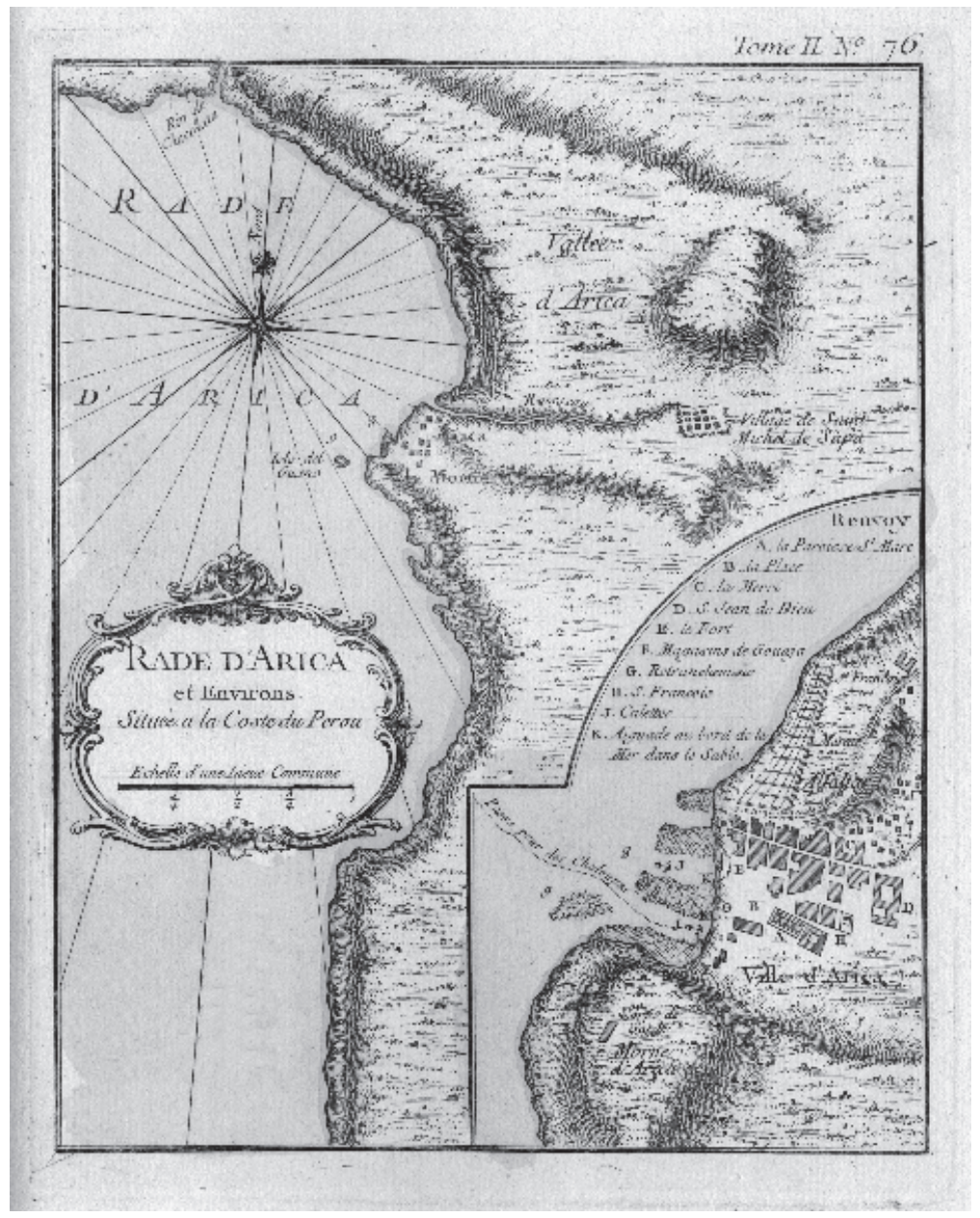

Puerto de Arica. En Jacques Nicolas Bellin, Le petit atlas maritime: recueil de cartes et plans des quatre parties du monde, París, s.n., 1764.

ción comenzó en septiembre de 1829, cuando se hizo cargo de cobrar a José de la Maza una serie de escrituras vencidas y distribuir en Arequipa las manufacturas europeas que Hellman le enviaba. Schutte era un mercader de cierta relevancia en esa ciudad, y un año atrás había conocido a Hellmann, cuando recurrió a la sucursal de Huth Grunning en Tacna para cobrar una letra vencida por 3.455 pesos a Dubern y Rejo ${ }^{49}$.

Seguramente la expansión a Arequipa fue exitosa, ya que un año más tarde se inauguró otra agencia en Potosí, a cargo del también alemán Federico Schwager, amplio conocedor de los mercados altiplánicos gracias a su experiencia anterior

49 ANA, leg. 77, fs. 337-337v, 24 de septiembre de 1829 
como agente de Lezica Hermanos y García. Su primera operación fue el cobro de un documento vencido por más de 2.400 pesos a José Manuel González ${ }^{50}$.

Tal vez el caso que grafica de forma más nítida la elección del eje Tacna-Arica como emplazamiento para articular operaciones mercantiles interregionales sea el de Begg, Atherson \& Co., que, a diferencia otras firmas comerciales europeas, instaló una filial en Tacna por propia iniciativa, antes que obligaciones de terceros la llevaran a nominar un apoderado.

La compañía, establecida en Lima, arribó a Tacna en agosto de 1826, designando como agente a José Santos Chocano, una influyente figura de la sociedad local que ofrecía un ventajoso punto de partida para cualquier emprendimiento mercantil, puesto que su familia controlaba importantes flujos de intercambio hacia Bolivia y su cuñado, José Santiago Basadre, era el principal comerciante criollo de la plaza ${ }^{51}$.

Dado que la especialidad de Begg Atherson era la distribución de manufacturas y el principal mercado de estas estaba en la región andina, en los siguientes meses designó subagentes en diversas ciudades del altiplano y la sierra, con el fin de cobrar deudas que mercaderes de esas localidades habían contraído, retirando mercaderías a crédito en Tacna. Estos apoderados además estaban investidos de atribuciones comerciales, ya que la intención era que se encargaran de distribuir localmente los efectos que Chocano les proporcionara, lo que en la práctica los convertía en agentes de Begg Atherson.

Uno de ellos fue Manuel Torres, que en mayo de 1828 recibió poderes de representación judicial para cobrar en Cochabamba 3.790 pesos y 5 reales a Francisco Cueto, por efectos de Europa que le fueron confiados seis meses antes en Tacna, a quien además se le confió la representación de la firma en cualquier negocio o asunto que estimara conveniente. Similar vínculo se estableció en julio de 1828 con el inglés John Nicholls, avecindado en Ayacucho, que debía cobrar 3.602 pesos a Marcelino Balbastro, mercader de esa plaza que un año antes había estado en Tacna aprovisionándose de manufacturas de ultramar ${ }^{52}$. Otro agente que dependía de la sucursal tacneña era Francisco Ignacio Medeyros, comerciante de Sucre que representaba localmente a Begg Atherson desde mayo de 1827, antes de que la firma tuviera algún compromiso específico en esa plaza ${ }^{53}$.

El posicionamiento de la casa británica en la región concluyó con la adquisición de una amplia vivienda en la calle principal de Arica, cerca de la plaza mayor y el puerto, empleada como local comercial y bodega, y que fue adquirida a la sucesión del escocés Andrew Macfarlane en la apreciable suma de 2.600 pesos $^{54}$. Sin embargo, la rápida expansión de Begg Atherson en la región bajo el influjo comercial del eje Tacna-Arica, junto a la estrategia de aproximarse a los consumidores finales mediante delegados encargados de la distribución a nivel local, evidenció fisuras prematuramente, ya que el desempeño de sus representantes en la

\footnotetext{
50 ANT, leg. 12, fs. 98-98v, 25 de septiembre de 1830.

51 ANA, leg. 72, fs. 69-69v, 17 de agosto de 1826.

52 ANA, leg. 77, fs. 83-83v, 3 de mayo de 1828; fs. 123-123v, 18 de julio de 1828.

53 ANA, leg. 73, fs. 85-85v, 28 de mayo de 1827.

54 ANA, leg. 77, fs. 124-128, 19 de julio de 1828.
} 
sierra y el altiplano no fue el esperado. Esto obligó a suprimir la figura del agente comercial local, limitarse a proporcionar mercaderías únicamente en la sucursal de Tacna y para el cobro de deudas en Bolivia, y designar apoderados temporales a comerciantes locales que viajaran a ese país, para quienes la relación con Begg Atherson fuese mucho más amplia y estable que la gestión particular encargada.

Ejemplo de ello son los poderes de representación entregados en marzo de 1829 a John Hegan, radicado temporalmente en Chuquisaca, para cobrar en esa ciudad 1.960 pesos a José María Ortega, por manufacturas europeas fiadas y cuyo plazo de vencimiento estaba próximo; en mayo siguiente aprovecharon un viaje de Joseph Hegan a Bolivia para encomendarle que se dirigiera a Cochabamba para cobrar a Francisco Cueto la misma deuda de 3.790 pesos y 5 reales que su anterior apoderado, Manuel Torres, no había logrado recolectar; y en octubre, similar encargo se le hizo a Frederick Salkeld, otro británico residente en Tacna que viajó a Bolivia a atender sus negocios particulares ${ }^{55}$.

Al parecer, el cambio de estrategia no logró mitigar los perjuicios que ocasionó a Begg Atherson la decisión de designar agentes locales en Bolivia, puesto que después de las gestiones comisionadas a Frederick Salkeld en aquel país, la última operación de la firma consignada en los protocolos notariales tacneños fue la enajenación de sus últimos activos, tres acciones de la Sociedad del Canal de Uchusuma, adquiridas por el propio Salkeld en septiembre de 1832. Para entonces, la sociedad ya estaba disuelta y el producto de la liquidación de sus bienes en Tacna correspondió a William Atherson, a la sazón avecindado en Puno ${ }^{56}$.

En definitiva, las casas comerciales europeas que se establecieron en Tacna durante la primera década de vida republicana en Perú supieron sacar partido de las cualidades geográficas de la región para sus operaciones en el Pacífico sudamericano. Si bien Tacna y sus satélites comerciales más directos, como Moquegua y Tarapacá, no constituían en sí un destino demasiado atractivo, las relaciones de intercambio con mercados más importantes, como Arequipa y Bolivia, dotados de un poder de consumo mucho más amplio, hicieron de Tacna un lugar perfecto para articular operaciones entre Valparaíso y esas regiones. En suma, los tradicionales vínculos de intercambio facilitaban la realización de nuevos emprendimientos mercantiles; la disposición en Arica de un puerto de desembarque permitía el control de las operaciones a distancia; y el desarrollo del comercio local, desde el último cuarto del siglo XVIII, había generado un ambiente propicio para este tipo de actividades.

Sin embargo, al analizar el destino de las distintas compañías extranjeras que operaron en la región en el transcurso de las décadas de 1820 y 1830, llama la atención el caso de Begg Atherson y su fracaso, en comparación al desempeño exitoso de otras firmas. La característica que diferencia a esta compañía de la mayor parte de las casas comerciales extranjeras es que, aunque también concentró sus actividades en el comercio de manufacturas, trató de diferenciarse de sus competidores aproximándose al consumidor final mediante la designación de agentes minoristas en diversas plazas.

55 ANA, leg. 77, fs. 242-242v, 26 de marzo de 1829; fs. 267-267v, 14 de mayo de 1829; fs. $362-$ $362 \mathrm{v}, 3$ de octubre de 1829 .

56 ANA, leg. 78, fs. 48-49v, 27 de septiembre de 1832. 
Esta fórmula suponía prescindir de las redes mercantiles locales y revestía dos riesgos que finalmente frustraron el proyecto: el primero fue que en los mercados locales operaban factores subjetivos fuera del alcance de los agentes de Begg Atherson y, por lo tanto, las decisiones de los consumidores estaban regidas por criterios que no eran racionales, como la desconfianza al extranjero y al no católico; y el segundo, que este mismo desconocimiento de los mercados y la distancia cultural con el público dificultaban el cobro de deudas y la ejecución de todo tipo de compromisos.

Otro aspecto fundamental que provocó el infortunio de la agencia de Begg Atherson en Tacna fue su errónea concepción del negocio minero. La firma hizo cuantiosas inversiones en Bolivia, como la adquisición de lavaderos de oro en el distrito de Tipuani, en 12.000 pesos, y una suma aun superior en la compra de yacimientos de cobre en el asiento de Corocoro. Estos depósitos ya habían sido trabajados durante la Colonia y eran considerados de bajísima productividad, por lo que el proyecto de los británicos se basaba en aplicar tecnologías modernas para su explotación, introducir hornos a carbón para la fundición, lo que permitiría aprovechar la escoria acumulada, y mecanizar al máximo las tareas del proceso productivo. Sin embargo, el negocio fracasó cuando los inversionistas comprobaron que el costo de trasladar la maquinaria y el combustible desde el puerto de Arica hasta el lugar de las faenas impedía toda posibilidad de obtener utilidades ${ }^{57}$.

Ciertamente, el fracaso minero de Begg Atherson no radicó en su intención modernizadora, sino en la falta claridad acerca de la etapa del proceso en que debían introducirse las innovaciones y en un profundo desconocimiento del escenario geográfico en que debían actuar, puesto que experiencias análogas, sin estas falencias, alcanzaron resultados exitosos. Un caso de estos es el del ingeniero alsaciano Charles Lambert, que en 1831 adquirió las escorias de un yacimiento cuprífero en las proximidades de la ciudad de Ovalle, en el norte de Chile, y las procesó en hornos de reverbero, similares a los que entonces se empleaban en Alemania e Inglaterra, logrando excelentes resultados ${ }^{58}$.

Mejor suerte que Begg Atherson tuvieron otras compañías extranjeras y empresarios independientes establecidos en la región, que primero se concentraron en las operaciones mercantiles y a partir de ellas se insertaron en los flujos de exportación de materias primas, de aquellas que ya operaban durante la Colonia, como la plata y la cascarilla, o de otras nuevas, como el salitre y la lana. Los primeros productos se obtenían como forma de pago por las manufacturas importadas que suministraban los empresarios extranjeros, mientras que los segundos demandaron de la organización de su explotación y transferencia.

Un caso que se ajusta a este perfil es el del francés Héctor Bacque, considerado uno de los pioneros de la industria del salitre en el siglo XIX, junto al chileno Santiago Zavala y los ingleses William Bollaert y George Smith. Hacia 1825 Bac-

57 Pentland, op. cit., 95-97.

58 Benjamín Vicuña Mackenna, El libro del cobre y del carbón piedra en Chile, Santiago y Buenos Aires, Editorial Francisco de Aguirre, 1978, 116-122. 
que era un pequeño mercader establecido en Tacna y dedicado a la venta de manufacturas y alimentos en Tarapacá, lo que le permitió aprovechar sus frecuentes viajes a esa provincia para recorrer la pampa, visitando las antiguas oficinas de parada que habían resultado destruidas o paralizadas durante las guerras de Independencia, con la expectativa de encontrar un depósito lo suficientemente provechoso como para ponerlo en funcionamiento y despachar nitrato de sodio a Europa, donde era empleado como insumo para la elaboración de pólvora y comenzaban a ser apreciadas sus cualidades como fertilizante agrícola.

A fines de 1826 sus exploraciones tuvieron éxito y fundó la oficina La Noria en un rico yacimiento ubicado en el desierto, 78 kilómetros al interior de Iquique. Los esfuerzos de Bacque y otros empresarios que se habían aventurado en el restablecimiento de la minería del salitre fueron favorecidos en 1828 con un decreto del gobierno del general José La Mar, que permitió la exportación de nitratos a Europa, ya que hasta entonces solo se comercializaban en Perú y Chile ${ }^{59}$.

Pero el hallazgo y denuncio de los caliches no bastaron a Bacque para echar a andar las faenas en La Noria, ya que carecía del capital indispensable para contratar obreros, adquirir herramientas y habilitar los planteles e instalaciones necesarias. En mayo de 1827 se trasladó a Lima con el propósito de atraer un socio capitalista o, por lo menos, conseguir un crédito que le permitiera iniciar las labores, dejando al paceño Antonio Freire a cargo de sus negocios en Tacna, con el especial encargo de cobrar las deudas pendientes a su favor que tenía en la plaza y en Tarapacá.

Al parecer las gestiones de Bacque en Lima tuvieron éxito, ya que antes de comenzar la producción de la oficina La Noria y convertirse, junto a Santiago Zavala, en el primer empresario en exportar salitre a Europa, Bacque consiguió recursos en el mercado local por apenas 1.157 pesos, mediante una letra que el 29 de junio de 1829 le giró la sucursal en La Paz de la casa española Dubern, Rejo y Cía., suma que por sí sola era insuficiente para solventar la puesta en marcha de los trabajos ${ }^{60}$. Para dar una idea de los costos involucrados en la producción y acarreo del salitre, se incluye un cuadro con el precio del flete entre una oficina de Bacque y la caleta de Pisagua, a 15 leguas de distancia, empleando una recua de 31 mulas.

COSTO DEL ACARREO DE SALITRE EN TRAYECTO DE 15 LEGUAS, EN 1832

\begin{tabular}{cccc}
\hline Trajines & Mulas & Carga & Precio \\
\hline 1 & 1 & 13 arrobas & 2 pesos 2 reales \\
1 & 31 & 403 arrobas & 65 pesos 7 reales \\
$48($ al año $)$ & 1.488 & 19.344 arrobas & 3.162 pesos \\
\hline
\end{tabular}

Fuente: ANA, leg. 78, fs. 175-178. 21 de abril, 1832.

59 Modesto Basadre, Riquezas peruanas, Lima, Editorial La Tribuna, 1884, 41; Óscar Bermúdez, Historia del Salitre. Desde sus orígenes hasta la Guerra del Pacífico, Santiago, Ediciones de la Universidad de Chile, 1963, 102-103.

60 Ronald Crozier, "La industria del Yodo, 1815-1915", en Historia 27, Santiago, 1993, 150-151. 
Aunque no son exhaustivos, porque seguramente sus actividades fueron formalizadas en diversos lugares, los registros de la notaría de Tacna ofrecen una visión panorámica de las actividades desarrolladas por Héctor Bacque en el negocio salitrero. En virtud de la arraigada tradición regional en torno a la arriería, el empresario francés acudía al pueblo cuando debía resolver el problema del transporte en las faenas y el acarreo de su producción hasta los puertos de embarque. De esta forma, en noviembre de 1831 compró a Lorenzo Olcay, vecino de Pica y residente en la quebrada de Camarones, catorce mulas y diez burros aparejados en 680 pesos que pagó al contado. Luego, suscribió un convenio con el arriero Felipe Berríos, mediante el cual este último puso a su disposición una recua de 25 mulas para trasladar hasta el puerto de Iquique la producción de una oficina denominada Nuestra Señora del Rosario, que Bacque tenía en sociedad con Felipe Bustos. Estimaron que cada mula podía transportar una carga con un volumen que oscilaba entre 7 y 15 arrobas, y su precio sería de 20 reales por carga, debiendo la recua efectuar un mínimo de seis viajes al año ${ }^{61}$.

En los meses siguientes aumentó la cobertura de los emprendimientos de Bacque. En abril de 1832 regresó a Tacna en busca de más facilidades de transporte. El día 21 contrató con José Ortiz González y José Manuel Rospigliosi, el primero de Tarata y el segundo de Pocollay, una recua de 31 mulas aparejadas destinada al trajín de la producción de una oficina salitrera de su propiedad y la caleta de Pisagua, distantes entre sí a 15 leguas. Se estimó la capacidad de carga de cada mula en 13 arrobas, a un precio de 17 reales cada trajín, debiendo efectuar, toda la recua, un mínimo de 48 trajines al año. Una semana después, Bacque suscribió un acuerdo similar con Juan de Dios Siña, dueño de una tropa de quince mulas ${ }^{62}$. Finalmente, seis meses después los requerimientos de flete entre la oficina de Bacque y la caleta de Pisagua debieron ser satisfechos mediante la incorporación de otras 16 mulas, propiedad de Pedro Telles y Antonio Solano, quienes lograron condiciones menos ventajosas que los primeros arrieros, ya que la capacidad de carga de sus animales fue estimada en 15 arrobas y cada trajín fue tasado en 12 reales $^{63}$.

La organización de las tareas extractivas y el beneficio de los caliches parecen haber concentrado la atención de Héctor Bacque, pues en noviembre de 1831 decidió confiar todo lo concerniente a la comercialización de su producción salitrera al irlandés John O'Connor, radicado en Iquique y dedicado a adquirir la producción de pequeñas oficinas, que luego colocaba en Valparaíso ${ }^{64}$.

La muerte de Bacque, en diciembre de 1832, puso fin prematuro a sus emprendimientos mineros e impide saber si, de haber obtenido utilidades, estas hubiesen sido invertidas en Tacna, en Tarapacá o retornado a su natal Burdeos. Aunque no hay certeza, al parecer su deceso fue consecuencia de un accidente, pues no alcanzó a testar y solo tuvo tiempo para formalizar la designación de su compatriota

\footnotetext{
61 ANA, leg. 74, fs. 33v-35, 4 de noviembre de 1831; fs. 4-5v, 10 de noviembre de 1831.

62 ANA, leg. 78, fs. 185-187, 21 de abril de 1832; ANA, leg. 80, fs. 40-44, 28 de abril de 1832

63 ANA, leg. 78, fs. 59-60, 31 de octubre de 1832.

64 ANA, leg. 78, fs. 231-231v, 24 de noviembre de 1831.
} 
Carlos Hertzog como albacea universal de sus bienes, encargándole liquidar las cuentas que tenía pendientes, operación de la que se desprende el hecho de que aún no había logrado utilidades que le permitieran cubrir los compromisos contraídos para poner en marcha las faenas que emprendió en la pampa de Tarapacá, ya que no señala persona alguna a quien hacerle llegar un eventual saldo favorable ${ }^{65}$.

Además, tal supuesto se afirma en el hecho de que la primera medida adoptada por Hertzog fue asegurar la continuidad de las faenas en las oficinas de Bacque, confiando esa tarea a John O'Connor, quien había trabajado estrechamente con el difunto, estaba familiarizado con la industria del nitrato en Tarapacá y, además, ya estaba a cargo de comercializar la producción del francés. Luego, se encargó de contactarse y negociar con los principales acreedores de Bacque en Lima, nombrando representante en esa capital a Juan Vidal, quien fue provisto de la atribución de saldar el pasivo con los derechos de Bacque sobre yacimientos y planteles de procesamiento ${ }^{66}$.

La liquidación de los bienes del empresario bordalés concluyó en abril de 1834, cuando Hertzog vendió en 1.000 pesos a John O'Connor una casa frente al puerto de Iquique, que era empleada como bodega almacén y pulpería, y una bodega en Pisagua en 650 pesos $^{67}$. El sistema productivo organizado por Bacque funcionó de gran forma bajo la tutela de O'Connor, pues en noviembre de 1837, después de cumplir 50 años de edad, el irlandés decidió retirarse y abandonar la aridez de Tarapacá para radicarse en Lima, vendió el local de Iquique al francés Bernardo Digoy, en 2.500 pesos, y delegó todos sus asuntos relacionados con la comercialización de salitres a Hugh Wilson, otro conspicuo mercader británico afincado en Tacna ${ }^{68}$.

Ciertamente, la minería del salitre fue el principal negocio de Tarapacá en el siglo XIX, aunque no todos quienes se aventuraron en él tuvieron la misma fortuna. Un caso distinto al de Bacque y su sucesor O'Connor fue el de la casa británica Cochrane \& Robertson. Advertida de las cualidades del salitre y sus expectativas comerciales, la firma basada en Lima, a través de su agente en Tacna William Black, adquirió varias estacas a pequeños beneficiadores tarapaqueños, así como un amplio local frente al puerto de Iquique para habilitar sus dependencias. La casa era la misma que luego perteneció a Héctor Bacque y más tarde a John O'Connor, y en esa ocasión fue comprada a los herederos de Pedro Langasica en 6.250 pesos, suma que casi triplica el precio que alcanzó el inmueble cuando ya la exportación de nitratos estaba en plena operación. Además, contrataron al ingeniero Benjamin Scott para organizar la explotación del caliche y dirigir las faenas.

Ambos antecedentes demuestran que Cochrane \& Robertson se había formado expectativas exageradamente optimistas sobre el futuro de la industria o, por lo menos, que el conocimiento de sus características y su contexto geográfico y cultural era escaso. Estas carencias redundaron en que la compañía dejó de figurar

\footnotetext{
65 ANA, leg. 78, fs. 36-37, 3 de diciembre de 1832 .

66 ANA, leg. 81, fs. 385-385v, 2 de enero de 1833; fs. 389-389v, 8 de enero de 1833 .

67 ANA, leg. 84, fs. 222-227, 14 de abril de 1834.

68 ANA, leg. 88, fs. 136-137, 27 de noviembre de 1837; fs. 139-141v, 14 de mayo de 1838.
} 
prematuramente en el elenco de empresarios y capitalistas salitreros, que liquidara rápidamente sus intereses e inversiones en Tarapacá y que el ingeniero Scott encontrara otros horizontes profesionales en el estudio técnico y diseño del canal de Uchusuma, anhelado proyecto hidráulico de los tacneños para regar el valle y aumentar significativamente el caudal del río Caplina ${ }^{69}$.

El caso de Cochrane y Robertson en el salitre en Tarapacá se asemeja a la también fallida incursión de Begg Atherson en la minería cuprífera en Bolivia, en el sentido de que ambas firmas invirtieron importantes sumas sin reparar en los numerosos aspectos culturales y geográficos que debían tenerse en cuenta antes de iniciar sus respectivos proyectos. Al parecer, estas compañías estaban motivadas por el ambiente de exagerado optimismo reinante en los centros financieros europeos y en las principales plazas sudamericanas, como Valparaíso, Lima, Buenos Aires y Río de Janeiro, así como en la noción de que toda modernización tecnológica sería provechosa.

En cambio, experiencias exitosas como la de Bacque, George Smith y Santiago Zavala coinciden en que estos empresarios, antes de aventurarse en la minería, ya conocían profundamente la región y la mentalidad de sus habitantes, por lo que sus decisiones partían de un conocimiento básico que comportaba un menor margen de riesgo. Esto se aprecia especialmente en la cautela que mostraron al introducir innovaciones técnicas, ya que en muchos ámbitos, como las faenas extractivas y el transporte, era más efectivo recurrir a los procedimientos tradicionales.

Otra importante materia prima en cuya exportación participaron activamente firmas europeas fue la lana de vicuñas, alpacas y ovejas, procedente de la sierra y el altiplano. Aunque su comercio era de larga data entre el Alto y el Bajo Perú, pues con él se fabricaban las telas rústicas destinadas al consumo de las comunidades indígenas y las clases populares, solo después de la independencia comenzaron a ser conocidas en Europa por su calidad. Un informe consular británico sobre Bolivia señala que en 1826 se remitieron a Francia cerca de 9 mil libras de lana de vicuña, en tanto que algunas muestras de lana de alpaca habían llegado a Gran Bretaña para evaluar la factibilidad de su uso industrial. Una década más tarde este rubro se había consolidado, ya que entre 1835 y 1842 por los puertos del sur peruano se exportaron 9.365 toneladas de lana de oveja y 19.076 toneladas de lana de vicuña y alpaca ${ }^{70}$. Aunque la mayor parte de las exportaciones de este producto se realizó por el puerto de Islay, recurriendo a intermediarios arequipeños, una pequeña porción transitó por Arica y estuvo al cuidado de una agencia mercantil tacneña ${ }^{71}$.

69 ANA, leg. 77, fs. 225-227v, 7 de marzo de 1829. Contrato entre la Compañía para el Regadío del valle de Tacna y el ingeniero Benjamin Scott, para que estudie el terreno y proponga un proyecto de canalización del río Uchusuma. Tiene un plazo de tres años y considera un sueldo de 250 pesos mensuales.

70 Alberto Flores Galindo, Arequipa y el sur andino, siglos XVIII-XX, Lima, Editorial Horizonte, 1976,75 .

71 Luciano Benjamín Cisneros, Ensayo sobre varias cuestiones económicas del Perú, Havre, Imprenta Lemale, 1866, 27. El autor entrega un cuadro estadístico de los productos exportados por los puertos peruanos en 1865 . 
El único caso de este tipo, aunque de no pequeña envergadura, que consignan los protocolos notariales de Tacna es el de Naylors, Kendall \& Co., que hasta bien entrada la década de 1830 había sido una de las tantas compañías mercantiles que surtía a los mercaderes locales con pequeñas partidas de telas europeas, vajilla, hierro y algunos productos chilenos, como bayeta de pellón y harina, en operaciones cuyo monto oscilaba entre 400 y 3.000 pesos $^{72}$. Sin embargo, sus actividades experimentaron una significativa expansión a partir de 1837, al parecer como consecuencia de haber logrado intermediar entre la demanda industrial británica por lana y algunos productores altiplánicos de esta materia prima.

En abril de ese año se reunieron en Tacna Bonifacio de Ayaldeburu y Samuel Oxley, el primero en representación del paceño José Garitán Zavala y el segundo como apoderado de Naylors \& Kendall, que a su vez representaba al industrial James Rawdon, de Liverpool. Allí acordaron que Garitán pondría a disposición de los ingleses 2.000 quintales de lana de cordero, blanca y lavada, en dos remesas iguales que se entregarían en Tacna, la primera entre los meses de agosto y septiembre próximos y la segunda treinta días después de verificada la primera. El precio acordado fue de 18 pesos por quintal, que serían cancelados con un adelanto de 12.000 pesos luego de la firma del contrato y dos cuotas similares una vez recibidos los envíos y comprobada su calidad por el apoderado del comprador ${ }^{73}$.

Aunque esta es la única operación de comercio de lana consignada en los archivos notariales de Tacna y Arica, por lo menos hasta 1840, seguramente porque dicho tráfico era operado desde Arequipa y utilizaba las instalaciones portuarias de Islay, ilustra una vez más el tipo de estrategia que resultó exitosa para las casas comerciales extranjeras establecidas en la costa del Pacífico sudamericano durante las décadas de 1820 y 1830 , que consistía en instalarse en los mercados locales y regionales como distribuidores de manufacturas importadas, para luego insertarse en algún flujo de exportación de materias primas, ya sea mediante la adquisición de estas a los productores, como en el caso de Naylors \& Kendall, Withington Crooke y los hermanos Hegan, o asumiendo directamente las tareas productivas, como Héctor Bacque ${ }^{74}$.

Más allá de su participación en la exportación de materias primas, estas casas comerciales compartían el hecho de insertarse en estos mercados a partir de la oferta de grandes volúmenes de objetos importados, y operar a través de redes

72 Antecedentes recopilados por la doctora Ana Cristina Mazzeo en el Archivo de la Aduana de El Callao.

73 ANT, leg. 10, fs. 301-302, 26 de abril de 1837; ANA, leg. 88, fs. 144-145v, 5 de mayo de 1837.

74 Manuel Burga y Wilson Reátegui, Lanas y capital mercantil en el sur. La casa Rickets, $1895-$ 1935, Lima, Instituto de Estudios Peruanos, 1981, 23-25. Aunque este trabajo analiza un período posterior, la posición de Naylors \& Kendall era similar a la que décadas más tarde seguían ostentando otras casas mercantiles arequipeñas especializadas en la comercialización de lana. Parte de sus ganancias radicaba en que intercambiaban esta materia prima por bienes importados, directamente con los hacendados productores o en las ferias cuando el ganado pertenecía a una comunidad indígena. En ambos casos otorgaban créditos, lo que les permitía ganar el diferencial entre la moneda dura, en que expresaban el precio de los productos que adquirían, y la feble (especialmente, la moneda boliviana), que utilizaban para sus compras. 
formadas por agentes, consignatarios y vínculos con clientes y otras firmas para el intercambio de información, compra venta de mercaderías y delegación de funciones mercantiles específicas, como el cobro de obligaciones vencidas y representación de demandas particulares ante las autoridades. Estas estrategias ya habían sido puestas en práctica por mercaderes criollos y peninsulares a partir de la década de 1780 , pero lo que distingue a los empresarios extranjeros, especialmente británicos, es su conducta más agresiva y dinámica, basada en cuantiosas inversiones, en la creación de una red de agentes para comenzar a operar y en la no conformidad con la obtención de utilidades únicamente comerciales.

En este sistema, la relación con los comerciantes criollos no fue de antagonismo, sino más bien de complementación, puesto que eran el eslabón a través del cual llegaban a los consumidores finales, les evitaba la tarea de cobrar deudas a personas con las que no tenían ningún tipo de afinidad ni proximidad y, por lo mismo, eran un medio eficaz para contratar todo tipo de servicios a nivel local.

\section{EL COMERCIO CRIOLLO Y LA ARRIERÍA}

Al comparar el escenario mercantil anterior y posterior a la independencia peruana en la región Tacna-Arica, destaca inmediatamente la desaparición de los grandes distribuidores peninsulares, desplazados por casas comerciales extranjeras, preferentemente británicas, que coparon las plazas del litoral Pacífico con una abundante oferta de manufacturas y sistemáticamente lograron controlar parte importante de las exportaciones de materias primas hacia el Viejo Mundo, ya sea como productores directos o como mediadores entre la oferta americana y la demanda europea. Además, esta transformación también afectó a los demás actores mercantiles de la región, que enfrentados a un nuevo escenario se vieron obligados a reformular la naturaleza de su quehacer económico y la intensidad de sus actividades.

El mundo de la arriería fue uno de los sectores impactados por la masiva llegada de mercaderes extranjeros, ya que el solo incremento de las mercaderías que arribaban al puerto de Arica con destino a otras regiones redundó en el aumento de la demanda por los servicios de flete. Pero también la disposición de una oferta más conveniente para obtener mercaderías importadas favoreció a aquellos troperos que combinaban el traslado de carga para terceros con la comercialización de partidas propias.

Un caso de este tipo es el del tacneño Egidio Siles, que hacia 1828 había forjado una sólida posición en base a una recua de cuarenta bestias que pacían en sus tierras de Calana y a dos viviendas que adquirió en el casco del pueblo ${ }^{75}$. El volumen de sus intereses lo condujo a encomendar a Ángel Gandolfo representarlo en el cobro de obligaciones a algunos vecinos de Cochabamba. Su principal proveedor era Horatio Bolton, que le fiaba diversos artículos de fácil colocación en el altiplano y lo esperaba al retorno de sus viajes para cobrárselos. Una de estas

75 ANA, leg. 77, fs. 31-35v, 28 de febrero de 1828. Testamento de Egidio Siles. 
operaciones tuvo lugar en mayo de 1828, cuando Siles recibió cinco zurrones de 150 libras de añil cada uno, al precio total de 1.593 pesos con 6 reales, que canceló tres meses después; o en abril de 1829, cuando Bolton le entregó 7.483 pesos en diversos efectos de Europa, que pagó cuatro meses después de recibidos ${ }^{76}$. Lamentablemente, en enero de 1832 una accidentada travesía por la sierra terminó con la muerte de Siles, la carga malograda y su viuda sin medios para responder a Bolton por los compromisos contraídos por el difunto, de modo que para saldar la deuda, la mujer debió traspasar uno de sus dos predios urbanos al empresario británico ${ }^{77}$.

Otro arriero que aprovechó de incursionar en el comercio transerrano fue Santiago Eyzaguirre, cuyo padre, José, había llegado desde Moquegua al valle de Lluta en 1804, donde logró organizar una recua de ochenta mulas y especializarse en el transporte de aceite, vino y aguardiente ${ }^{78}$. Santiago Eyzaguirre comenzó a combinar la prestación de servicios de flete para terceros con la venta de productos por su cuenta. La rápida expansión de sus intereses lo obligó, en diciembre de 1827, a designar a Ignacio Ortega representante general en Bolivia, especialmente con la tarea cobrar deudas en Potosí y La Paz ${ }^{79}$; pero también lo puso bajo la lupa de las autoridades, que en febrero de 1834 sospecharon que su recua de treinta y cinco mulas cargada con efectos de ultramar adquiridos en Tacna, en lugar de dirigirse a La Paz, trasladaba pertrechos para el general Miguel San Román, que había levantado a la guarnición de Puno contra el gobierno de Luis José de Orbegoso. Para continuar el viaje, el subprefecto José Justo Arias obligó a Eyzaguirre a regresar a Tacna y dejar en la notaría todos sus bienes en prenda a favor de la prefectura de Arequipa ${ }^{80}$.

Junto con la posibilidad de incursionar en la colocación de especies importadas, el comercio extranjero ofreció a los empresarios de la arriería la posibilidad de prestar servicios de transporte en los emprendimientos mineros en que comprometían sus utilidades comerciales mercantiles, como la explotación de nitratos en Tarapacá. Los empresarios salitreros comenzaron a acudir a la plaza de Tacna para contratar servicios de arriería desde noviembre de 1831, cuando Héctor Bacque reclutó las recuas de Francisco Berríos y Felipe Bustos para el laboreo de su oficina Nuestra Señora del Rosario. Cuatro años después, los arrieros tacneños no alcanzaban a cubrir toda la demanda, y desde regiones aledañas acudían otros troperos en busca de un contrato para partir a la pampa con sus animales. Por ejemplo, en 1835 el francés Bernard Digoy, establecido en Iquique y propietario de la oficina Elizalde, a través de sus compatriotas Esteban Casey y Carlos Hertzog contrató el servicio de 63 mulas para el acarreo de la producción de su establecimiento hasta dicho puerto: en enero, contrató con José María Coya, procedente del valle de Lluta, 12 mulas aparejadas; en marzo, Marcelino Portales, natural de

76 ANA, leg. 77, fs. 25-25v, 15 de febrero de 1828; fs. 82-82v, 1 de mayo de 1828; fs. 262-262v, 8 de abril de 1829 .

77 ANA, leg. 80, fs. 13-14v, 1 de febrero de 1832 .

78 ANA, leg. 66, fs. 120-124, 6 de mayo de 1820. Testamento de José Eyzaguirre.

79 ANA, leg. 73, fs. 209-209v, 7 de diciembre de 1827.

80 ANA, leg. 84, f. 284v, 21 de febrero de 1834. 
Calana, aportó 16 bestias; y en abril, el tacneño Domingo Blanires puso a su disposición otras $35^{81}$.

Otro industrial salitrero que acudía a Tacna para resolver sus necesidades de transporte era George Smith, que a través de la agencia local de Hegan \& Hall contrató para el servicio de la oficina Colombia 70 mulas, propiedad de los arequipeños Alejandro Medina, Gregorio Pontigo y Mariano Zegarra, y otras 30 a los tarapaqueños Mariano Morales y Mariano Murcia, que para cumplir con los requerimientos exigidos por los representantes de Smith debieron comprar 12 animales a Santiago Eyzaguirre, criados en sus haciendas del valle de Azapa ${ }^{82}$.

Además de los arrieros, había comerciantes europeos establecidos en Tacna que no controlaban la distribución de grandes volúmenes de mercadería y que tenían como clientes a numerosos pequeños mercaderes y pulperos que operaban a nivel local o recorrían las aldeas, caseríos y comunidades indígenas de la región, vendiendo los productos que les eran adelantados. Entre los pequeños tenderos se cuentan Bárbara Lerna, dueña de un baratillo en el valle de Lluta, que en septiembre de 1828 recibió de Alexander Macartney 416 pesos en diversos efectos que se comprometió a pagar en mensualidades de 17 pesos; el español Manuel Tejeiro que tenía una tienda en Arica, a la entrada del valle de Azapa, y que era habilitado por el británico John Broben; o el matrimonio ariqueño formado por Juan Bedoya y Juana Albarracín, que regentaba una pulpería cerca del puerto, donde además de alimentos y licores ofrecían diversos artículos elaborados que Daniel Mackenzie les suministraba a crédito ${ }^{83}$.

De una envergadura algo mayor fueron las operaciones en que se comprometieron aquellos mercaderes dedicados a recorrer las áreas periféricas del partido, ya sea porque optaron por especializarse en atender la demanda de lugares que, por su lejanía y reducida capacidad de consumo, no atraían el interés de otros comerciantes, o porque agregaron el comercio de bienes importados a la distribución de otros productos especialmente destinados a la actividad agrícola. Tal es el caso del ariqueño Joaquín Ramírez, dedicado a la extracción de guano y que hacia 1829 era el principal abastecedor de José Santiago Basadre, quien comercializaba grandes partidas de este abono natural en el altiplano.

En un convenio suscrito en enero de 1829, ambos empresarios acordaron intercambiar guano por mercaderías, lo que le permitió a Ramírez disponer de nuevos productos que ofrecer a los agricultores, campesinos y comunidades indígenas de la provincia que visitaba para venderles el fertilizante ${ }^{84}$. La relación con Basadre fue efímera y nada feliz, pero Ramírez persistió en la distribución de manufacturas en sectores periféricos de la región. En noviembre del mismo año obtuvo de Fermín Rejo un adelanto de 1.676 pesos en efectos de ultramar, que se obligó a satisfacer

81 ANA, leg. 85, fs. 138-139, 22 de enero de 1835; fs. 108-109, 30 de marzo de 1835; fs. $127-$ 128v, 22 de abril de 1835.

82 ANA, leg. 83, fs. 19-19v, 19 de junio de 1835; ANA, leg. 85, fs. 83-85, 19 de junio de 1835; ANA, leg. 86, fs. 448-449, 13 de abril de 1836

83 ANA, leg. 77, fs. 143-143v, 1 de septiembre de 1828; ANA, leg. 71, fs. 70-71, 4 de febrero de 1829; ANA, leg. 86, fs. 280-282, 18 de agosto de 1836.

84 ANA, leg. 74, fs. 331-331v, 3 de enero de 1829. 
dentro de seis meses, con un interés de medio punto por cada mes de atraso ${ }^{85}$. Los cálculos de Ramírez fueron excesivamente optimistas, ya que en enero de 1831 obtuvo de William Swinburn 1.668 pesos en efectivo, para cubrir sus deudas con Basadre y Rejo, suma que se comprometió a restituir entregando 500 pesos dentro de un mes y el saldo en seis meses más ${ }^{86}$. Pero tampoco pudo responder a este compromiso y en enero de 1833 debió recurrir a un nuevo crédito, esta vez por 2.401 pesos, proporcionados ahora por Luis Stevenson, aunque con la salvedad de que la mitad serían saldados mediante la entrega de guano en la bahía de Ilo $^{87}$. Transcurridos más de siete años, Ramírez logró disminuir el pasivo, pero no extinguirlo del todo, de modo que para terminar definitivamente con sus deudas, pidió prestados 1.000 pesos a Mariano Calderón Portocarrero, garantizando su devolución en el plazo de un año con la transferencia de una deuda a su favor contraída por Magdalena Cuenca, agricultora de Lluta, y con la hipoteca de su propia vivienda en Arica ${ }^{88}$.

Aunque la estrategia mercantil seguida por Joaquín Ramírez parecía obedecer a sensatos cálculos, es decir, complementar la tradicional distribución de guano en las áreas rurales de la provincia con la venta directa de efectos importados que obtenía en el comercio de Tacna y Arica, a la larga se encontró sobrepasado por las deudas, por el mayor ritmo de incremento de su pasivo en relación al de su ingreso y por el hecho de que le resultaba más dificultoso hacer efectivas las obligaciones que sus clientes contraían con él -en su mayor parte labradores e indígenas, cuyas deudas consistían únicamente en tratos de palabra, tremendamente difíciles de cobrar-, que contener los embates de sus acreedores, con quienes debía suscribir acuerdos formales, aceptar multas pecuniarias por mora y comprometer garantías hipotecarias en caso de incumplimiento. Esta distancia entre su proyecto comercial, concebido racionalmente, y la realidad obedece a que en la práctica Joaquín Ramírez se entregó a una aventura empresarial solo, al margen de todas las redes de intercambio que operaban en la región desde el período colonial y de las que comenzaron a funcionar luego del advenimiento de la independencia peruana, desprovisto de toda información comercial a partir de la cual incrementar sus utilidades y sin posibilidades de almacenar o redireccionar sus existencias, lo que lo relegaba a ser el tercer o cuarto eslabón en la cadena de distribución de manufacturas.

Distinto fue el caso del limeño José Suárez Inclán, que llegó a la región a formar parte de la red de la familia González Vigil. Su hermano mayor, Manuel, era abogado y desde 1801 atendía los intereses de esas familia en la capital, relación a partir de la cual contrajo matrimonio con María del Carmen, la hija mayor de Joaquín González Vigil ${ }^{89}$. Inicialmente, el matrimonio se radicó en La Paz, donde Suárez Inclán colaboró estrechamente con su cuñado, Joaquín Ex Helme, a

85 ANA, leg. 77, fs. 385-385v, 4 de noviembre de 1829.

86 ANA, leg. 78, fs. 320-320v, 27 de enero de 1831.

87 ANA, leg. 81, fs. 369-369v, 7 de enero de 1833 .

88 ANT, leg. 11, fs. 321-321v, 13 de agosto de 1840

89 ANA, leg. 58, fs. 378-379, 18 de febrero de 1801. José Antonio González Vigil designa a Manuel Suárez Inclán para que atienda sus asuntos comerciales en Lima; ANA, leg. 61, fs. 210v-211, 1 de febrero de 1805. Joaquín González Vigil entrega poderes de representación judicial y comercial en Lima a Manuel Suárez Inclán. 
cargo de los negocios de la red González Vigil en el Alto Perú. Su arribo a Tacna data de abril de 1826, cuando llegó al pueblo con una pareja de esclavos que vendió al escocés Andrew Macfarlane en 500 pesos ${ }^{90}$. Luego se dedicó a suministrar grandes partidas de efectos manufacturados a mayoristas regionales que ya trataban habitualmente con la familia González Vigil, como el puneño Alberto Juárez y los paceños Victoriano Gurruchaga y Lorenzo Flores ${ }^{91}$. Para atender a clientes de menor envergadura y, especialmente, para cobrar deudas, Suárez Inclán llegaba a acuerdos de colaboración mutua con mercaderes ya vinculados con la familia, quienes representaban sus intereses en diversas plazas regionales, como Antonio González en Arequipa, José Sánchez en Huancavelica, Pedro Antonio Cifuentes en Lima y el propio Victoriano Gurruchaga en La Paz ${ }^{92}$.

Al fallecer en marzo de 1838, José Suárez Inclán dejó a su viuda en una holgada posición. Con la mayor parte de los compromisos comerciales pendientes cubiertos con el capital monetario acumulado por su esposo, la mujer quedó como propietaria de una espaciosa y finamente alhajada vivienda en Tacna, una hacienda en las afueras del pueblo cuyo alquiler le proporcionaba un ingreso de 700 pesos anuales, más de 4.000 pesos en deudas por cobrar en Bolivia y una red familiar en condiciones de auxiliarla en caso de necesidad ${ }^{93}$.

Otro mercader que logró adaptarse exitosamente a la irrupción del comercio europeo en la región fue el español Francisco Agustín de Gondra, que se posicionó como intermediario entre la oferta de manufacturas importadas disponibles en el eje Tacna-Arica y la demanda regional por estos productos, especialmente en el altiplano. Gondra desembarcó por primera vez en el puerto de Arica a fines de diciembre de 1820, a bordo de la fragata inglesa Thaix, procedente de Valparaíso, a cargo de un voluminoso cargamento de telas y paños de Castilla destinado al mercader paceño Juan Manuel de las Muñecas ${ }^{94}$. Aunque en los libros de la Aduana de Arica se lo consigna como el dueño de dicha mercadería, es probable que Gondra estuviese ayudando a ocultar la identidad del verdadero propietario, el comerciante limeño y partidario de la causa realista Francisco Javier Izcué, que se asoció con el entonces desconocido Gondra, en previsión de una nueva depredación por parte de la escuadra o el ejército del gobierno de Chile. Hasta 1817, Izcué mantuvo una sucursal en Valparaíso, desde donde distribuía manufacturas, azúcar y cacao y acopiaba trigo y otros alimentos que posteriormente enviaba a Perú ${ }^{95}$.

$90 \quad$ ANA, leg. 72, fs. 137-139v, 11 de abril de 1826 .

91 ANA, leg. 73, fs. 197-198, 26 de noviembre de 1827; ANA, leg. 77, fs. 45-45v, 11 de marzo de 1828; fs. $67 \mathrm{v}-68 \mathrm{v}, 26$ de abril de 1828 .

92 ANA, leg. 72, fs. 88-88v, 29 de septiembre de 1826; ANA, leg. 73, fs. 55-55v, 31 de marzo de 1827; ANA, leg. 77, fs. 91-91v, 17 de mayo de 1828 .

93 ANA, leg. 82, fs. 164-164v, 13 de abril de 1838; fs. $112 \mathrm{v}-113 \mathrm{v}, 10$ de mayo de 1838 .

94 Archivo General de la Nación (Perú). Sección Colonial. Fondo Real Aduana de Arica, leg. 156, cuaderno 399, 29 de diciembre de 1820.

95 En Chile Izcué operaba en sociedad con los españoles Pedro Nicolás de Chopitea y Celedonio Villota, quienes recibían las manufacturas que traía desde Lima y lo surtían de bienes alimenticios producidos en el país. Mario Cárdenas, Consecuencias económicas y sociales del proceso de emancipación en Chile: El caso de los secuestros de bienes a patriotas y realistas, 1813-1853, Tesis para optar al grado de Doctor en Historia, Pontificia Universidad Católica de Chile, Santiago, 1998, 73. 
Después de la derrota de Chacabuco, esta agencia fue allanada por orden del general San Martín, su documentación incautada y la existencia de la bodega requisada. Las pérdidas sufridas no desanimaron al limeño, que persistió en el comercio en el litoral del Pacífico, para lo que se valió de otros mercaderes menos conocidos que él, como Gondra, a quienes transfería mercadería de su propiedad y encomendaba su entrega, convencido de que el producto de las ventas le sería restituido una vez concluida la operación. Pero los cálculos de Izcué fueron errados, sus cómplices lo traicionaron y terminó sus días en la ruina, aunque sus herederos persiguieron judicialmente, por más de una década, a quienes defraudaron su confianza ${ }^{96}$.

Ya en Arica, Francisco Agustín de Gondra estableció contacto con los mercaderes locales para aprontar los detalles necesarios para el viaje a La Paz y emprendió tratativas para organizar nuevos negocios. Para desaduanar la mercadería de las bodegas del puerto, obtuvo la fianza de Nicolás Buteler y dejó a otro español, Rafael Peró, a cargo de la obtención de vinos y licores en el mercado regional, con miras a una nueva expedición a la sierra ${ }^{97}$. Ignoramos el desenlace de estas operaciones, pero debieron haber sido fructíferas, así como las relaciones cimentadas en el Alto Perú, pues cuatro años más tarde Francisco Agustín de Gondra, asociado con el tacneño Francisco Telles, suministraba considerables partidas de efectos importados a mercaderes bolivianos, como Lorenzo Flores y José Fermín Pizarro, a quienes en septiembre de 1825 despachó una remesa de 10.792 pesos en manufacturas europeas, que fueron pagadas mediante la entrega de 8.000 pesos al momento de la recepción de la carga y el saldo en un plazo de treinta días ${ }^{98}$.

Los siguientes años fueron provechosos para los negocios de Gondra, que logró hacerse un lugar en el medio mercantil tacneño. En la villa estaban radicados sus habituales proveedores de manufacturas, como Andrew Macfarlane, Horatio Bolton y Fermín Rejo, a quienes además asistía en el cobro de obligaciones vencidas a clientes bolivianos ${ }^{99}$. Además, allí disponía de una abundante oferta de servicios de arriería para enviar sus remesas de mercadería a diversas plazas en el altiplano o en la sierra. El volumen de sus operaciones no ameritaba la designación de apoderados permanentes, pero cuando no podía acompañar personalmente a las recuas, confiaba la representación de sus intereses al arriero Nicolás Céspedes ${ }^{100}$. Los contactos establecidos en Bolivia le permitieron conformar una cartera de clientes

96 ANA, leg. 73, fs. 139-139v, 18 de agosto de 1827. Avenimiento entre Francisco Agustín de Gondra y el hijo de Francisco Javier Izcué, Juan Francisco, para el pago de los 12.000 pesos en que avaluaron las mercaderías que el primero recibió en 1820, siempre y cuando se presentara la documentación que acreditara el traspaso de los bienes en cuestión. Cinco años después, Izcué seguía reclamando a Gondra, en los tribunales de Lima, el dinero defraudado a su padre (ANA, leg. 78, fs. 177-177v, 6 de marzo de 1832). Otro de los mercaderes afincados en Tacna perseguido por los herederos de Izcué fue Fernando Ex Helme, que en 1827 reconoció compromisos por 20.000 pesos, llegando a sufrir el embargo de sus bienes en junio de 1831 (ANA, leg. 73, fs. 59v-59v, 6 de abril de 1827).

97 ANA, leg. 67, fs. 131-132, 24 de febrero de 1821; fs. 132v-133, 28 de febrero de 1821.

98 ANA, leg. 70, fs. 70-71, 17 de septiembre de 1825 .

99 ANA, leg. 73, fs. 26-26v, 17 de febrero de 1827; fs. 76-76v, 5 de mayo de 1827; ANA, leg. 77 , fs. $103-104 \mathrm{v}, 14$ de junio de 1828 .

100 ANA, leg. 73, fs. 57v-58v, 3 de abril de 1827. 
que, si bien no controlaban un volumen considerable de sus respectivos mercados locales, podían mantenerse en actividad permanente ${ }^{101}$.

Como otros mercaderes criollos, Francisco Agustín de Gondra ocupó una posición intermedia entre los distribuidores mayoristas de manufacturas que coparon las plazas del Pacífico a partir de la segunda mitad de la década de 1820 y los redistribuidores de estos bienes en los mercados del altiplano y la sierra. De igual manera que sus predecesores en la última etapa del período colonial, Gondra sobrevivió en el comercio de las manufacturas, a partir de contactos que le permitieron posicionarse ventajosamente entre la oferta y la demanda. Tacna era una plaza conveniente para abastecerse de importaciones de ultramar, y los mercados regionales a los que tenía acceso desde allí disponían de un tipo de clientes medianos a los que podía atender sin entrar en competencia con sus propios proveedores.

\section{CONCLUSIONES}

Es posible que para los habitantes de la región Tacna-Arica el masivo arribo de comerciantes noratlánticos, después de la independencia, no pasara inadvertido y que muchos experimentaran la sensación de estar viviendo tiempos completamente distintos al de sus padres y los de su propia infancia. Sin embargo, estas transformaciones imputables a la llegada de estos mercaderes y que terminaron con la inserción de la economía regional en el sistema capitalista mundial no tienen otro origen que las reformas borbónicas del período virreinal, y particularmente la promulgación del Reglamento de Libre Comercio en 1778, estatuto a partir del cual el puerto de Arica comenzó a recibir (formalmente) naves, primero directamente desde España y otras colonias del Imperio y, luego de la independencia, desde diversos rincones del mundo ${ }^{102}$. Los mercaderes locales dejaron de depender únicamen-

101 ANA, leg. 73 fs. 8-8v, 20 de enero de 1827. Una de sus pocas contrapartes bolivianas que se menciona en los protocolos de la notaría de Tacna es el paceño Manuel Zumarán, antiguo socio de José Santiago Basadre, cuyos acuerdos con Gondra fueron formalizados probablemente en atención a su cuantía.

102 Esta constatación no es novedosa y ha ya sido destacada en estudios relativos a la historia económica peruana, de otras colonias americanas y a nivel mundial. Por ejemplo, Carlos Contreras, analizando el comportamiento de los distintos sectores productivos, concluye que "El 'modelo económico colonial borbónico' no estaba, pues, agotado en 1821; el proceso de independencia vino en realidad a interrumpir el desarrollo de una economía que, de la mano de un acertado plan de modernización, daba francos pasos hacia el progreso" (Carlos Contreras, El aprendizaje del capitalismo. Estudios de historia económica y social del Perú republicano, Lima, Instituto de Estudios Peruanos, 2004, 27-28). Para el caso del comercio chileno finicolonial, Eduardo Cavieres verifica la imposibilidad de concebirlo únicamente a partir de su tutelar subordinación a Lima, debiendo abordarse "inserto a la economía-mundo: los comerciantes santiaguinos con fronteras muchísimo más lejanas que las estrechas vinculaciones político-administrativas o económico-sociales con Lima" (Eduardo Cavieres, El comercio chileno en la economía-mundo colonial, Valparaíso, Ediciones Universitarias de Valparaíso de la Universidad Católica de Valparaíso, 1996, 14). Desde una óptica global, el mismo fenómeno es destacado por Immanuel Wallerstein, al señalar que "En el curso de la renovada expansión económica (e inflación monetaria) del período 1733-1817, la economía-mundo europea rompió los límites que había creado durante el siglo XVI y comenzó a incorporar vastas zonas nuevas a la división efectiva del trabajo que ya abarcaba. Empezó incorporando zonas que ya se encontraban en su área externa desde el siglo XVII, en concreto y sobre todo el subcontinente indio, el imperio otomano, 
te del comercio limeño para obtener manufacturas importadas, ya que estos bienes comenzaron a llegar desde la costa atlántica del continente, por la ruta del Alto Perú, o bien desde Cádiz, en navios de permiso por la ruta del cabo de Hornos. De esto se deriva que tampoco la articulación con otros núcleos del comercio subcontinental, como Valparaíso, Buenos Aires, Montevideo, e incluso Río de Janeiro, sea una novedad aportada por los empresarios llegados desde el hemisferio norte.

En cuanto a las redes de intercambio regional, su origen es incluso anterior al reformismo borbón, y se puede admitir que los antiguos corregidores se desempeñaban como virtuales distribuidores regionales de algún mayorista limeño, para lo cual recurrían a los servicios de arrieros, mercaderes locales y hacendados. Esta integración explicaría la amplia protección que recibían estos magistrados cuando eran perseguidos judicialmente por las autoridades coloniales, que comprendía desde los procesos ventilados en la Audiencia de Lima hasta las declaraciones hechas por los vecinos más importantes de su distrito. Con la eliminación de los corregidores y el reparto de mercancías en 1784, estos tejidos de relaciones comerciales comenzaron a funcionar plenamente en la región, impulsados por la expansión de los mayoristas peninsulares que se asociaban con intermediarios locales para despachar al Alto Perú y los mercados regionales los productos que controlaban; por otros comerciantes, españoles y americanos, de inferior envergadura pero provistos de una actitud dinámica (agresiva) que les permitió hacerse presentes en diversas plazas del Pacífico, cosechando sus utilidades en el diferencial de los precios existente entre una y otra; y por mercaderes locales que establecían acuerdos de colaboración con sus pares de otras villas, con el objeto de intercambiar productos para incrementar la variedad de su oferta y auxiliarse mutuamente en cuestiones administrativas, judiciales y comerciales.

La utilización de la función financiera en el comercio regional tampoco es una novedad del período de la temprana República peruana, ya que es posible encontrar primitivas formas de crédito en los adelantos de diversos enseres con que los mercaderes tacneños habilitaban a los arrieros y en las ventas a plazo con que negociaban la colocación de manufacturas en los mercados regionales, en las que la fijación de un interés por mora fue habitual desde la década de 1790. Entonces, la singularidad de los empresarios extranjeros en este ámbito radicó en la mayor intensidad con que emplearon este tipo de mecanismos, llegando a constituirse, junto con los préstamos de dinero, en un negocio distinto al comercio. Provistas de una dinámica propia, las operaciones crediticias alcanzaron una cobertura insospechada en tiempos posvirreinales, ya que no era extraño encontrar en la notaría de Tacna la formalización de reclamos por obligaciones contraídas en Buenos Aires, Montevideo, Lima, Santiago y Valparaíso, plazas a partir de las cuales el mercado local se conectaba con la economía mundial.

Otro rasgo de la estrategia seguida por los comerciantes noratlánticos asentados en Tacna y Arica después de la independencia, fue el insertarse en los flujos de

el imperio ruso y África Occidental. Estas incorporaciones tuvieron lugar en la segunda mitad del siglo XVIII y en la primera mitad del XIX [...]" (Immanuel Wallerstein, El moderno sistema económico mundial, México, Siglo XXI Editores, 2006, $2^{\text {a }}$ edición en español, III: 179). 
exportación de materias primas, luego de consolidada su posición en el medio local a partir de la distribución de manufacturas importadas. Esta estrategia, en la que la "fase exportadora" aparece como la continuidad lógica de la "fase mercantil", fue antes empleada por los mercaderes limeños cuando debieron enfrentar la eliminación de sus privilegios monopólicos y la competencia de Buenos Aires en los mercados regionales, a los cuales tuvieron acceso exclusivo hasta las reformas de Carlos III. A nivel regional, esto se aprecia en la intención de los mercaderes locales y peninsulares arribados durante las dos últimas décadas del siglo XVIII, de transformar sus excedentes en metales preciosos, de preferencia plata, y de acceder al control de materias primas, como la cascarilla, de creciente demanda en el Viejo Mundo. Esto sin considerar la actividad del contrabando, que también puede ser considerado parte del flujo exportador.

En definitiva, el advenimiento del comercio extranjero en la región TacnaArica estuvo lejos de eliminar las redes de intercambio que operaban desde las postrimerías del período colonial, salvo la sustitución de los grandes distribuidores mayoristas, limeños y peninsulares. Por el contrario, recurrió a las tramas existentes para colocar sus productos en los mercados regionales y locales, mediante el concurso de distribuidores intermedios, minoristas y arrieros, que en conjunto se acoplaron al sistema de intercambio mundial. Además, el capital comercial arribado del Viejo Mundo estimuló el desenvolvimiento de actividades productivas destinadas a la exportación, lo que alentó el fortalecimiento y la diversificación de la base económica local y regional.

Tal vez la gran diferencia en relación al período anterior es que durante el Virreinato los flujos comerciales que transitaban por el territorio tacnoariqueño estaban sometidos a un régimen político e institucional superior e inaccesible, en el que los intereses locales y regionales debían necesariamente subordinarse al proyecto imperial. Con la formación de los estados nacionales americanos esta distancia disminuyó drásticamente y el poder público dejó de ser un objeto distante e inmutable, dando lugar a que sectores productivos y regiones específicas compitieran entre sí para imponer un régimen normativo favorable a sus intereses. Entonces, en un Estado como el Perú poscolonial, en el que este tipo de demandas más que ser diversas eran antagónicas, los conflictos económicos y las fricciones regionales tendieron a resolverse en la arena política, cuando no en la militar. 